
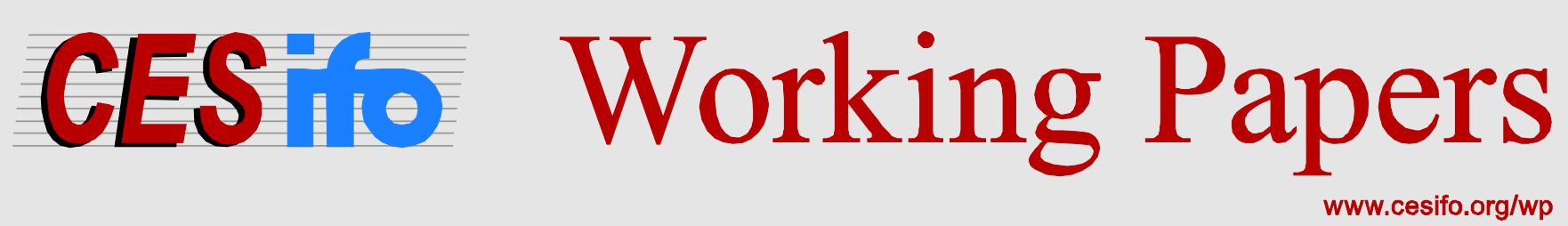

\title{
Do Multinationals Transfer Culture? Evidence on Female Employment in China
}

\author{
Heiwai Tang \\ Yifan Zhang
}

CESIFO WORKING PAPER NO. 6295

CATEgory 8: TRAde Policy

JANUARY 2017

An electronic version of the paper may be downloaded

- from the SSRN website:

- from the RePEc website:

- from the CESifo website:

www.SSRN.com

www.RePEc.org

www.CESifo-group.org/wp 


\title{
Do Multinationals Transfer Culture? Evidence on Female Employment in China
}

\begin{abstract}
We study the global diffusion of culture through multinationals, focusing on gender norms. Using data on manufacturing firms in China over 2004-2007, we find that foreign affiliates from countries with a more gender-equal culture tend to employ proportionally more women and appoint female managers. They also generate cultural spillovers, increasing domestic firms' female labor shares in the same industry or city. Based on a multi-sector model with firm heterogeneity in productivity, gender biases, and learning, we perform counterfactual exercises. Hypothetically eliminating firms' gender biases raises China's aggregate total factor productivity by $5 \%$, of which spillovers from multinationals account for $19 \%$.
\end{abstract}

JEL-Codes: F110, F210, J160, L220, O470.

Keywords: cultural spillover, gender inequality, FDI, misallocation.

\author{
Heiwai Tang* \\ School of Advanced International Studies \\ Johns Hopkins University \\ 1717 Massachusetts Ave NW \\ USA - Washington, DC 20036 \\ hwtang@jhu.edu
}

\author{
Yifan Zhang \\ Department of Economics \\ Chinese University of Hong Kong \\ Shatin, New Territories \\ Hong Kong \\ yifan.zhang@cuhk.edu.hk
}

*corresponding author

December 28, 2016

We thank seminar and conference participants at Bank of Finland's Institute for Economies in Transition, Boston U, Cornell, CUHK, HKUST, ILO, Indiana, Inter-American Development Bank, Johns Hopkins SAIS, Keio, Kobe, Shanghai Jiaotong, RIETI, Syracuse, Tsinghua, Virginia, Waseda for their helpful comments and discussions. We thank Andrei Levchenko for sharing data; Ann Harrison, Chang-Tai Hsieh, and Michael Song for comments; and Liuchuan Deng and Yui Law for excellent research assistance. The usual disclaimer applies. 


\section{Introduction}

Multinationals have been an important vehicle for cross-country flows of ideas, capital, and technology. ${ }^{1}$ Besides their roles in advancing global economic convergence, social scientists have long written about how multinationals can also shape host countries' social norms and values, leading to cultural convergence across countries. ${ }^{2}$ Economics research on the cultural effects of foreign direct investment (FDI) has been scant, in part because of the challenges in quantifying culture, let alone identifying its diffusion.

This paper contributes to the debate on the cultural effects of globalization, by studying how multinational firms transmit gender norms from their countries of origin to the host countries. We use microdata on manufacturing firms in China to study cultural transfers within multinational firm boundaries and cultural spillovers to domestic firms. By inferring firms' attitudes towards women based on their female labor shares within a narrow industry, we find that foreign affiliates from countries with a more gender-equal culture tend to employ proportionately more women and appoint female managers. Specifically, based on two measures of home country's gender norms - an outcome-based Gender Inequality Index from the United Nations Development Program (UNDP) and a survey-based measure constructed based on the responses in World Values Surveys - we find that a one standard-deviation decrease in the UNDP Gender Inequality Index of the country of origin (equivalent to reducing Malaysia's gender inequality to that of Germany) is associated with an average 1.9 percentage point higher female labor share in its affiliates, after controlling for 4-digit industry and province fixed effects. These results remain robust even after controlling for a wide range of firm characteristics, including skill intensity and several measures of technology.

Perhaps more surprisingly, multinational firms are also found to generate cultural spillovers to domestic firms, as evidenced by the finding that both domestic firms' average female labor share and likelihood of having a female manager increase with multinationals' output or employment share in the same industry or city. In particular, after controlling for firm fixed effects and other previously explored determinants, we find that a one standard-deviation increase in multinationals' output share in the same city (industry) is associated with an average $1.7(0.7)$ percentage-point increase in a domestic firm's female labor share. Such cultural spillovers from multinationals are stronger if the source country has a more gender-equal culture, suggesting that the changes in domestic firms' female labor shares are not solely driven by stiffer competition in the goods or labor markets.

To guide our empirical analysis on cultural transfers and spillovers, and quantitatively study the effects of gender biases and the cultural effects of FDI on firm and aggregate efficiency, we

\footnotetext{
${ }^{1}$ See the literature reviews by Harrison and Rodriguez-Clare (2010) and Alfaro (2016).

${ }^{2}$ Writings on cultural homogenization and clashes are widespread, ranging from Thomas Friedman's (1999) famous work that claims "No two countries with McDonald's have ever gone to war since each got its McDonald's," to the classic book "The Clash of Civilizations and the Remaking of World Order" by Samuel Huntington (1996). See the literature review for details.
} 
build a parsimonious multi-sector task-based model based on Acemoglu and Autor (2011), which features firm heterogeneity in productivity and biased perceptions about female labor costs. The model focuses on firms' labor demand and assumes inelastic labor supply by both female and male workers. Workers of the same gender have identical productivity, while women have a comparative advantage in skill- rather than physically-intensive tasks. Firms sell horizontally differentiated varieties in monopolistically competitive sectors, which differ in the intensity of skilled tasks. With female workers' all specialized in supplying skills, production functions micro-founded on tasks with varying skill intensities can then be expressed as Cobb-Douglas production functions with constant cost shares for female and male labor.

We incorporate in this set up firms' taste-based discrimination, à la Becker (1957). Specifically, each firm draws its own subjective variable cost of female labor and productivity from two separate distributions, before entering a market. Countries with a more gender-equal culture are represented by distributions of firms' subjective female labor costs that have lower mean and variance. Biased perceived costs of female workers, compared to the objective benchmark, cause firms to employ fewer female workers, thereby lowering profits. Indeed, we find in our data a positive correlation between a firm's profit and its female-to-male labor ratio, after controlling for firm fixed effects, suggesting that gender discrimination is costly.

We model cultural spillovers as a process of domestic firms updating their (biased) beliefs about the cost of female workers towards the objective benchmark, similar to the cultural transmission models of Bisin and Verdier (2000, 2011) and Fernandez (2013). Specifically, a domestic firm updates its prior belief about the cost of female workers if its prior differs from the average belief among foreign firms it interacts with, particularly when the number of foreign firms is higher. Our model also predicts stronger cultural transfers and spillovers in female labor-intensive industries (i.e., when women have a comparative advantage in production). All these predictions on spillovers are supported by our firm-level regressions. In the appendix, we show that the same set of theoretical predictions can be obtained in an alternative model with statistical discrimination, à la Phelps (1972) and Arrow (1973).

The last part of the paper quantifies the aggregate productivity losses due to gender discrimination, and the gains associated with the cultural effects of FDI. Applying the average revenue product approach proposed by Hsieh and Klenow (2009; henceforth HK) and Restuccia and Rogerson (2013) in the context of our model, along with data on female labor shares across U.S. industries, we find that eliminating gender discrimination altogether, by setting all firms' female-to-male labor ratios to the corresponding U.S. benchmark by industry, is associated with a $5 \%$ increase in aggregate manufacturing total factor productivity (TFP) (compared to a 33\% TFP gain by removing all capital distortions). The cultural effect of FDI, through reducing the dispersion of firms' discrimination behaviors by about one-fifth, is estimated to have contributed about $1 \%$ of China's aggregate manufacturing TFP. 
China's gender inequality is an interesting case to study. ${ }^{3}$ The foundation of Chinese culture, Confucian philosophy, advocates a strict obligatory role for women. In the traditional Chinese patriarchal society, men were viewed as superior and women were expected to follow the leadership of men in the family, typically the father before marriage and the husband after. Since the establishment of People's Republic of China in 1949, gender inequality significantly subsided under Mao's egalitarian policies. ${ }^{4}$ The female labor force participation rate soared, with more women becoming government leaders and role model workers in state-owned enterprises. However, such policy-induced reduction in gender inequality took a reverse trend, after the central government implemented market-oriented economic policies and phased out Mao's social policies since the late 1970s (Cai, Zhao and Park, 2008). ${ }^{5}$

This paper contributes to several strands of literature spanning broad social science disciplines. It adds to a large body of work in sociology and anthropology on the relation between globalization and culture (e.g., Hofstede, 1980; Pieterse, 2003; Hopper, 2007), ${ }^{6}$ by providing empirical support for the pure theories or case studies about the "cultural convergence" hypothesis.

It is related to the economics literature on culture. Economists have identified systematic differences in social norms and people's beliefs across countries, and to relate them to various microeconomic phenomena, such as saving, participation in the financial market, investment in education, and preferences for redistribution (Guiso, Sapienza, and Zingales, 2006; Fernandez, 2011), as well as macroeconomic outcomes, such as economic growth (Gorodnichenko and Roland, 2016), trade and FDI between countries (Guiso, Sapienza, and Zingales, 2009). Recent research empirically examines channels through which cultural values can be transmitted from one country to another (e.g., Fisman and Miguel, 2007; Maystrea et al., 2014). Related to gender norms specifically, research shows that progress has been slow as prejudices against certain groups in society often have their deep historical roots (Jayachandran, 2015). Such hypothesis has been empirically verified by Alesina, Giuliano, and Nunn (2013), who show that the descendants of societies that practiced plough agriculture more intensively in the past have less equal gender norms today. Our paper illustrates how a globalization event can quickly change culture, which is often considered as slow-moving institutions (Roland, 2004). ${ }^{7}$

\footnotetext{
${ }^{3}$ Gender prejudice has been shown to have a significant impact on China's macroeconomic outcomes, such as saving rates (Wei and Zhang, 2011). Instead of studying the consequences of discrimination, we provide evidence that FDI can be used as a vehicle to change social norms.

${ }^{4}$ For instance, in the 1950 s women won the right to own property and land, as well as the right to vote. Women gained the freedom to marry and divorce for the first time in Chinese history after a marriage law was passed in 1950.

${ }^{5}$ According to a survey of more than 3,000 women conducted in 2009 by the Center for Women's Law and Legal Services at Peking University, more than 20 percent say employers cut salaries for women who become pregnant or give birth and 11.2 percent lost their jobs after having a baby. More than one third of the surveyed women believed that male employees have more opportunities for getting promotion.

${ }^{6}$ Social psychologist Hofstede (1980) show how a country's culture is multi-dimensional and determined by both internal and external forces. Sociologists Pieterse (2003) and Hopper (2007) study how economic globalization can change participating countries' cultures. They examine three paradigms: the "clash of civilizations," "McDonaldization" and hybridization.

${ }^{7}$ A recent paper by Kodama, Javorcik, and Abe (2016) also find that in Japan, the share of women in overall
} 
Given our focus on firms' revealed preferences for female labor, it relates to the extensive literature on gender and racial discrimination (e.g., Altonji and Blank, 1999; Bertrand and Mullainathan, 2004; Bertrand, 2011; Duflo, 2012). Becker (1957) in his classic work hypothesized that the more discriminating firms will be driven out of business in the long run by the less discriminating ones through market competition. Several studies have empirically verified Becker's hypotheses in the context of trade (Borjas and Ramey, 1995; Black and Brainerd, 2004; Juhn, Ujhelyi, and VillegasSanchez, 2014). ${ }^{8}$ Recent research attempts to quantify the cost of discrimination (Hsieh et al., 2016; Cavalcanti and Tavares, 2016). For example, Hsieh et al. (2016) find that about a quarter of the aggregate output growth per worker between 1960 and 2008 can be explained by an increasingly more efficient allocation of talent across gender and racial groups. ${ }^{9}$ Complementing their findings, we provide the first piece of firm-based quantification of the economic cost of discrimination and the cultural effect of FDI through reducing gender inequality.

Finally, our paper contributes to the extensive literature on the effects of FDI on the host countries. Existing studies of FDI spillovers focus almost exclusively on knowledge and technology spillovers (e.g., Aitken and Harrison, 1997; Javorcik, 2004; Branstetter 2006; Keller and Yeaple, 2009). We explore whether and how FDI may transfer culture and shape social norms in the host countries. Our findings suggest that the gradually closing gender gap in some developing countries could be partially attributed to a previously unexplored aspect of FDI - gender cultural spillovers.

The rest of the paper proceeds as follows. Section 2 introduces our theoretical model. Section 3 discusses our data source and measurements. Based on our theory, Section 4 tests the main model predictions about the transfers and spillovers of gender cultural values from multinationals. Section 5 quantifies the aggregate productivity loss due to gender discrimination and the aggregate efficiency gain associated with the cultural spillovers from FDI. The last section concludes.

\section{Model}

To guide our empirical analysis on cultural transfers and spillovers and quantify firm and aggregate efficiency losses due to gender biases, we build a parsimonious multi-sector task-based model with firm heterogeneity in productivity, biases towards female workers, and learning within sectors or

employment as well as in the management staff are on average higher, while the gender wage gap is smaller in foreign affiliates than in domestic firms. Foreign affiliates also tend to implement female-friendly human resource policies. Our paper goes beyond the cultural transfer effects by studying the mechanism of cultural spillovers and the associated the associated productivity gains.

${ }^{8}$ Black and Brainerd (2004) find that competition due to trade liberalization lowers the gender wage gap in the U.S. Juhn et al. (2014) show that trade liberalization in Mexico reduces gender inequality, especially among blue collar workers, as the intensive use of machines by new exporters replaces physically demanding tasks for which male workers have a comparative advantage.

${ }^{9}$ A recent report by the McKinsey Global Institute (2015) illustrates the economic cost of gender biases in different countries. Using Japanese firm data, Kawaguchi (2007) finds that the impact of gender discrimination on firm profits and growth is small. 
regions. We outline the key features and results of the model in the main text, relegating all technical details and proofs to the appendix.

\subsection{Set-up}

\subsubsection{Environment}

Consider an economy with a three-layer structure: industries (sectors), firms, and tasks. The economy is endowed with $M$ male workers and $F$ female workers, who have identical preferences. Consumers consume goods based on a Cobb-Douglas utility function with constant expenditure shares $\theta_{j}$ over industries indexed by $j=\{1,2, \ldots, J\}$. To be discussed later, industry index $j$ also indicates the degree of female comparative advantage. Within an industry, consumers have DixitStiglitz preferences with constant elasticity of substitution (CES) between varieties equal to $\sigma_{j}>1$. Upon paying fixed costs to operate in an industry, firms sell horizontally differentiated varieties in the monopolistically competitive market, with each firm facing an isoelastic demand curve

$$
y_{i}=A_{j} p_{i}^{-\sigma_{j}}
$$

where $A_{j}$ is the demand factor of industry $j$ and $p_{i}$ is the price of a variety sold by firm $i .{ }^{10}$

\subsubsection{Labor Supply}

The supply side of the model is built on Acemoglu and Autor's (2011) Ricardian model of the labor market. Each worker has one unit of time and has to decide how to allocate the time on supplying skilled and physically intensive (brawn) labor units in order to maximize labor income. Workers of the same gender have identical productivity, while women's relative productivity in skill-intensive tasks are higher than men, as assumed by Pitt, Rosenzweig, and Hassan (2012). ${ }^{11}$

In the appendix, we show that the no-arbitrage wage condition implies that female workers will allocate all their time to supply only skills, while male workers will supply only brawn. The idea is that wages will adjust to reflect workers' comparative advantage, in the same fashion prices adjust to reflect countries' comparative advantage in the standard Ricardian trade model. In equilibrium, both female and male workers will therefore completely specialize in what they are relatively better at.

\footnotetext{
${ }^{10} A_{j}=E_{j} P_{j}^{\sigma_{j}-1}$, where $E_{j}$ is the aggregate expenditure on industry- $j$ goods.

${ }^{11}$ Obviously this strong result depends on the simplifying assumption that all men have the same comparative advantage in brawn and skills. A richer setup involves different distributions of comparative advantage between men and women, with the former group having a higher mean of relative endowment of physically intensive labor inputs.
} 


\subsubsection{Production}

We now turn to the labor demand side. We can simply assume that industries differ in female labor intensity, as in Do, Levchenko and Raddatz (2016). However, we build the micro-foundation for that usual approach using a task-based model (see the appendix for details).

A firm needs to employ skilled and brawn labor inputs to produce a variety of tasks. It then combines a continuum of tasks, based on an industry-specific Cobb-Douglas production function, to produce final goods. While tasks vary in skill intensity, as in Acemoglu and Autor (2011), industries differ in their relative dependences on skill-intensive tasks. The appendix shows how a Cobb-Douglas production function with constant cost shares of skilled and brawn inputs can be derived based on a task-based model. The basic idea is that a firm decides whether to use either skills or brawn to produce each task. In equilibrium, given prices for skills and brawn inputs, all tasks above a certain skill intensity cutoff are always produced with skills only, while tasks below that cutoff are always produced with brawn only. Therefore, industries that are relatively more dependent on skill-intensive tasks will be female labor-intensive, given that female workers completely specialize in supplying skills as described above, and male workers completely specialize in supplying brawn inputs.

A Cobb-Douglas production function with female and male labor can then be derived as

$$
y_{i j}=\varphi_{i} \mu_{j} f_{i}^{\beta_{j}} m_{i}^{1-\beta_{j}}
$$

where $\varphi_{i}$ is firm $i$ 's total factor productivity and $\beta_{j}$ is the industry-specific cost share of female workers. $\mu_{j}$ is a industry-specific constant that depends on the parameters of the underlying taskbased model (see the appendix for details). Firms are heterogeneous in productivity, as in Melitz (2003). Before entering a market, a firm draws $\varphi_{i}$ from a common distribution function $G(\varphi)$ over $[0, \infty)$.

\subsection{Cultural Transfers}

A novel feature of our model is that some firms are biased in their views about the cost of employing women, and choose a suboptimal ratio of female to male workers. Firms are different in their perceived variable costs of female labor, as in Becker (1957). Specifically, a firm's prior belief about the variable cost of female labor is $1+\gamma$, which is assumed to be log-normally distributed with mean $\psi \geq 0$ and variance $\nu>0$ :

$$
\log (1+\gamma) \sim N(\psi, \nu)
$$

Following the seminal paper by Phelps (1972), we assume that firms from countries that are more biased against women hold beliefs that are characterized by higher average (i.e., a higher $\psi$ ) and 
variance of $\gamma$ (i.e., higher $\nu$ ). ${ }^{12}$ The idea that the variance of $\gamma$ is increasing in the degree of the prejudice against women in society is based on the literature on statistical discrimination, which assumes a higher uncertainty about the labor cost (or productivity) of the discriminated group. ${ }^{13}$ An ideal country that is unbiased against women is therefore characterized by $\psi=\nu=0$.

One may wonder why a firm does not adjust immediately to the true (objective) value of $\gamma$, even when losing profits. There are an abundance of examples showing that people's perceptions about the attributes of certain groups in society are often shaped by simple rule-of-thumb judgements. Thus, it takes time for the prejudices to change, even when they cause deviations from individuals' optimal choices (Alesina, Giuliano, and Nunn, 2013). ${ }^{14}$

We first focus on solving for a firm's equilibrium and suppress both firm and industry subscripts for notational ease. Upon drawing a parameter bundle $(\varphi, \gamma)$, a firm from a particular market has revenue equal to $R(\varphi, \gamma)=A^{1-\eta}\left(\varphi f^{\beta} m^{1-\beta}\right)^{\eta}$, with $A$ summarizing all factors that affect market demand, taken as given by firms, and $\eta=1-\sigma^{-1}$.

Based on its productivity, $\varphi$, and perceived variable cost of female labor $\gamma$, a firm chooses labor demand for both gender to maximize expected profit as:

$$
\pi(\varphi, \gamma)=\max _{f, m}\left\{R(\varphi, \gamma)-w_{f}(1+\gamma) f-w_{m} m-\phi\right\}
$$

where $\phi$ is the fixed cost measured in the final consumption aggregates. The firm is said to be unbiased when $\gamma=0$, or favor female workers if $\gamma<0$.

The first order conditions of the problem imply the following firm's female-to-male labor ratio:

$$
\frac{f}{m}=\frac{\beta}{(1-\beta)(1+\gamma)} \frac{w_{m}}{w_{f}}
$$

It is clear that all else equal, a firm's $\frac{f}{m}$ is decreasing in $\gamma$, the firm's perceived female labor cost, but increasing in the industry's female labor intensity $(\beta)$.

In the absence of gender biases (when $\gamma=0$ ), the unbiased female-to-male labor ratio should be $\frac{\beta}{1-\beta} \frac{w_{m}}{w_{f}}$. Consider two FDI's countries of origin $\left(c\right.$ and $\left.c^{\prime}\right)$, with country $c$ having a more genderequal culture represented by $\psi_{c}<\psi_{c^{\prime}}$ and $\nu_{c}<\nu_{c^{\prime}}$. We should expect that a firm from $c$, due to a lower expected $\gamma$, has a higher average $\frac{f}{m}$. Let us summarize these results in the following proposition.

Proposition 1 Firms from countries that hold a more biased view about female labor costs (i.e., a higher $\psi$ ) have a lower average female-to-male labor ratio within an industry. The relation-

\footnotetext{
${ }^{12}$ A higher average $\gamma$ can deliver outcomes that are consistent with gender biases at the firm level. However, in the data, we observe a significant variation in female-to-male labor ratios across firms even within a narrow industry.

${ }^{13}$ See Fang and Morro (2010) for a summary of the literature on statistical discrimination.

${ }^{14}$ Becker (1957) also postulates that when the whole society (all firms) holds the same prejudice, market competition will not drive the discriminating firms out of business.
} 
ship is quantitatively stronger in the more female labor-intensive industries (a higher $\beta$ ).

\subsubsection{Discussion on Statistical Discrimination}

Even we assume that discrimination is taste-based, the results regarding the female-to-male labor ratio in (3) can also be obtained in a model with statistical (information-based) discrimination. In the appendix, we show another version of the model that features statistical discrimination. In that model, firms draw different perceived female productivity parameters from a known distribution, instead of drawing female labor cost parameters. Under the intuitive assumptions that firms in countries with a stronger bias against women hold beliefs associated with a lower average but a higher variance (uncertainty) of perceived female labor productivity, eq. (3) will take a similar form but with firm-specific $\beta_{i}$, which is decreasing in the firm's bias against women. In other words, regardless of the type of discrimination, our model predicts a negative correlation between firms' gender biases and their female labor shares.

\subsubsection{The Effects on Firm Profits}

We now examine the effects of gender discrimination on firm and aggregate economic outcomes, respectively. Substituting the firm's privately optimal choices of female and male workers into its production and profit functions yields output as

$$
y(\varphi, \gamma)=A\left[\frac{\eta \varphi D}{c(\gamma)}\right]^{\sigma}
$$

and profit as

$$
\pi(\varphi, \gamma)=A(1-\eta)\left(\frac{\eta \varphi D}{c(\gamma)}\right)^{\sigma-1}-\phi
$$

where $D=\beta^{\beta}(1-\beta)^{1-\beta}, c(\gamma)=w_{f}(1+\gamma)^{\beta} w_{m}^{1-\beta}$.

It is obvious that both firm output and profit are decreasing in $\gamma$. Moreover, these relationships depend on $\beta$, the industry's female labor intensity, since

$$
\frac{\partial}{\partial \beta}\left|\frac{\partial \pi(\varphi, \gamma)}{\partial \gamma}\right|>0
$$

We thus have the following proposition.

Proposition 2 All else being equal, firms that are more biased against women have lower profits, especially in the more female labor-intensive industries. 
Even when taste-based discrimination does not directly affect wages, prices need to adjust ex post to equalize a firm's supply and demand for its goods, according to the subjective cost of employing female workers and thus a suboptimal (from the economic or social point of view) level of female employment. Using the firm's demand curve (1) and $y(\varphi, \gamma)$ from (4), we can solve for its price and revenue TFP (TFPR) as

$$
\begin{gathered}
p(\varphi, \gamma)=\frac{c(\gamma)}{\varphi \eta D} \\
T F P R(\gamma)=p(\varphi, \gamma) \varphi=\frac{c(\gamma)}{\eta D}
\end{gathered}
$$

A higher $\gamma$, through increasing the variable cost of production, raises $p(\varphi, \gamma)$ and $T F P R(\gamma)$. Intuitively, a biased view about female labor costs lowers the firm's quantity supplied and raises its price. A higher TFPR appears to be a positive outcome, but readers who are familiar with the literature on resource misallocation should not be surprised by this counter-intuitive result. The positive relationship between TFPR and distortion (in this case the discrimination factor) is driven by higher prices, given constant markups and wages. It is important to note that a higher firm's TFPR should not be interpreted as higher efficiency.

HK highlight that an industry's TFP is negatively related to the dispersion of firms' TFPRs in the industry. The rationale is that in the absence of discrimination, firms' individual optimizations equalize TFPRs to the same constant that depends on the industry-specific constant elasticity of substitution for goods and common factor prices. The fact that firms' TFPRs are more dispersed reflect more pronounced underlying distortions on factor prices. Under the assumption that discrimination and productivity are independently distributed, industry $j$ 's distorted TFP can be expressed as

$$
\log T F P_{j}=\log T F P_{j}^{e}-\frac{\sigma_{j} \beta_{j}}{2} \nu_{j}
$$

where $T F P^{e}$ is the efficient level of industry TFP when discrimination is absent (i.e., $\psi=\nu=0$ ). All else being equal, an industry's TFP is lower if the dispersion of the discrimination factors $\left(\nu_{j}\right)$, the cost share of female workers $\left(\beta_{j}\right)$, and/ or the elasticity of substitution between final good varieties $\left(\sigma_{j}\right)$ are larger. ${ }^{15}$ The economy's aggregate TFP, based on consumers' Cobb-Douglas utility function, can be expressed as $T F P=\prod_{j=1}^{J} T F P_{j}^{\theta_{j}}$.

Proposition 3 A larger variation in firms'gender biases within an industry is associated with a lower industry TFP, thereby reducing aggregate TFP.

Our model focuses on gender discrimination as a cause of a higher dispersion of firms' TFPRs.

\footnotetext{
${ }^{15}$ In Section 5, we will consider output and capital distortions, and permit correlations between all distortions in the computation of the productivity losses.
} 
In reality, there can be many different sources of distortions that deliver similar results, such as differences in capital and output distortions, due to government policies. Through the lens of our model, in Section 5 we will study the productivity losses due to gender biases, along with output and capital distortions.

\subsection{Cultural Spillovers}

The second part of our model studies whether multinational affiliates induce domestic firms to employ more women. Domestic firms may respond to higher FDI in the same market for two reasons - competition and learning (imitation). Regarding competition, the entry of foreign invested enterprises (FIEs) into a market may drive up input costs but lower final good prices. Both effects lower profits for all firms, possibly inducing some of them to employ more women. This is particularly true for the least productive firms who are concerned about survival.

We hypothesize that domestic firms, after observing the decisions and outcomes of FIEs in the same market (industry or city), will update their beliefs about female workers. Over time, domestic firms update their beliefs towards the "average" level of $\gamma$ observed in their market, based on the FIEs they interact with. If there are more FIEs from countries with a less biased view about female workers, domestic firms' adjustment of biased beliefs will be even larger.

Let us introduce the information structure under which domestic firms observe other firms' inferred preferences and in turn change their employment decisions. To illustrate the main theoretical points, we consider only one foreign country of origin. Generalizing the model by considering FIEs from multiple countries will only complicate the expressions without changing the main theoretical predictions qualitatively.

Consider a domestic firm that observes imperfectly FIEs' $\gamma$ with noise in the same market (city or industry). ${ }^{16}$ The "signal" the firm observes, $z$, can be expressed as

$$
z=\psi^{*}+\varepsilon^{*}+\xi
$$

where $\psi^{*}$ is the mean of the observed beliefs about $\log (1+\gamma)$, held by the FIEs from a foreign country of origin (denoted by $*$ ). The parameter $\varepsilon^{*}$ is a firm-specific female labor cost, relative to the mean, of FIEs. It is normally distributed with mean 0 and variance $\nu^{*}$. We make no assumption about whether $\psi^{*}$ is larger than $\psi$ or not, nor about the variances of $\varepsilon^{*}$ and $\varepsilon$. FIEs in the same market may well hold a more biased view against women, compared to domestic firms on average. The parameter $\xi \sim N\left(0, v_{w}\right)$ is an observational white noise, assumed to be distributed independently of $\varepsilon^{*}$. Therefore, from the firm's point of view, the error of the "signal" observed

\footnotetext{
${ }^{16}$ The assumption that the firm observes its neighbors' female labor costs seems strong. Alternatively, we can make a more intuitive assumption that the firm observes its neighboring firms' female-male labor ratio, which the firm can then infer the subjective labor cost of an observed FIE as $1+\gamma=\frac{m}{f} \frac{\beta}{1-\beta} \frac{w_{m}}{w_{f}}$.
} 
has two components: $\varepsilon^{*}$ and $\xi$. For notational simplicity, let us define $\lambda^{*}=\varepsilon^{*}+\xi$ and rewrite (8) as

$$
z=\psi^{*}+\lambda^{*}
$$

where $\lambda^{*}$ is normally distributed with mean 0 and variance $\omega=\nu^{*}+\nu_{w}$.

How does this signal help the domestic firm update its own prior beliefs? Based on $\bar{z}^{\prime} s$ inferred from $n$ neighbors, the firm updates its prior according to Bayes' rule. The posterior belief is normally distributed with the following mean $\psi^{\prime}: 17$

$$
\psi^{\prime}(n, \bar{z}) \equiv E[\log (1+\gamma) \mid n, \bar{z}]=\delta \bar{z}+(1-\delta) \psi,
$$

where $\delta$ is the weight the firm puts on the observed (sample) mean $\bar{z}=\frac{1}{n} \sum_{l=1}^{n} z_{l}$, based on observed $z$ 's from $n$ neighboring firms. According to DeGroot (2004), $\delta$ can be derived as

$$
\delta(n, v, \omega)=\frac{n v}{\omega+n v}=\left(1+\frac{1}{n} \frac{\omega}{v}\right)^{-1}
$$

Partial differentiation yields the following comparative statics regarding the relationship between the number of neighbors and the average signal observed from FIEs:

$$
\frac{\partial \psi^{\prime}}{\partial n}=(\bar{z}-\psi) \underbrace{\frac{\partial \delta}{\partial n}}_{>0} .
$$

Eq. (11) shows that the spillover effect is generally stronger if there are more FIEs whose signals are observed, as a firm will put a larger weight $\delta$ on other firms' signals about their beliefs and a smaller weight on its own prior belief. However, the direction of belief updating will depend on whether $\bar{z}-\psi$ is positive or not. If the observed FIEs hold a less biased view toward women than the firm itself (i.e., $\bar{z}<\psi$ ), a greater number of FIEs induces a larger extent of belief updating toward 0 . On the other hand, more biased views held by FIEs observed by the domestic firm (i.e., $\bar{z}>\psi$ ) will lead to belief updating away from 0, especially when there are more FIEs observed. These theoretical results are summarized in the following proposition.

Proposition 4 Domestic firms' female labor shares are increasing in the prevalence of FDI in the same industry or city, if the average FIEs' belief is more gender-equal.

We know from eq. (7) that a higher dispersion of firms' TFPRs within an industry implies a greater extent of resource misallocation and thus a lower industry-level TFP. Our model shows that the dispersion of TFPRs will change, through firms' Bayesian updating based on the behaviors

\footnotetext{
${ }^{17}$ See Chapter 9 of DeGroot (2004).
} 
of the FIEs observed. Specifically, the posterior variance of a firm's $\gamma$, given $n, v$, and $\omega$, can be expressed as

$$
v^{\prime}(n, v, \omega)=\frac{\omega v}{\omega+n v}=\left(\frac{1}{v}+\frac{n}{\omega}\right)^{-1},
$$

which has the following properties:

$$
\frac{\partial v^{\prime}}{\partial n}<0 ; \frac{\partial v^{\prime}}{\partial v}>0 ; \frac{\partial v^{\prime}}{\partial \omega}>0
$$

The precision of the posterior, $1 / v^{\prime}$, increases with the number of neighbors revealing the signal. Moreover, if either the precision of the signal or the precision of the prior belief is lower, the posterior belief will be noisier.

To sum up, when FIEs in the same market are less biased against female workers (i.e., $\psi^{*}<\psi$ and $v^{*}<v$ ), they are more likely to employ proportionately more women than domestic firms. The presence of these FIEs in the same market induce the latter to increase their female employment. Such social learning leads to a change in social norms in the labor market, which we interpret as evidence of cultural spillovers. The opposite will be true if FIEs hold a less favorable view towards women (i.e., $\psi^{*}>\psi$ and $v^{*}>v$ ).

Using eq. (3), we can show that the cultural spillover effect on a firm's female-to-male ratio is stronger in industries in which women have a comparative advantage, as

$$
\frac{\partial}{\partial \beta}\left[\frac{\partial\left(\frac{f}{m}\right)^{2}}{\partial n \partial(-\bar{z})}\right]>0 .
$$

The idea is that the marginal benefit of belief updating is greater in female labor-intensive industries. This section ends with the following proposition.

Proposition 5 The spillover of gender norms from multinational affiliates to domestic firms is stronger in the more female labor-intensive industries.

\section{Data Sources and Summary Statistics}

\subsection{Firm-Level Data}

The primary data for our analysis are drawn from the annual industrial firm surveys of China for the period of 2004-2007. The surveys, conducted by the country's National Bureau of Statistics (NBS), cover all state-owned firms and all non-state firms that have sales over 5 million RMB (about 0.7 million USD in the 2007 exchange rate). Basic firm balance sheet information, such as 
output, value added, fixed asset, exports, employment, as well as industry code and ownership type (foreign or domestic in particular) are available. Despite the sampling threshold, the data are quite representative. Compared to the 2004 economic census, the aggregate data based on our firm data accounted for 91, 71, 97, and 91 percents of China's total industrial output, employment, exports, and fixed assets, respectively. To construct a panel data set, we use unique firm ID as well as firm contact information to identify the same firm across years. ${ }^{18}$ We calculate firm real capital stock and TFP, following the methods proposed by Brandt, Van Biesebroeck and Zhang (2012).

Most importantly, we use the following firm variables to construct a firm's female labor share, the main variable of interest in our regression analysis:

1. For 2004, we have information on firm employment by gender and education level. A worker is considered as skilled if $\mathrm{s} /$ he has education of high school or above. About 39 percent of total employment in our data set are considered skilled in $2004 .{ }^{19}$

2. For 2005, 2006 and 2007, we have information on employment by gender but not education levels.

Our firm data do not have information on workers' wages by gender. With this limitation, we focus on studying gender biases based on the varying female labor shares across firms. ${ }^{20} \mathrm{~A}$ firm's foreign ownership status is identified based on its registration. We obtain information on FIEs' countries of origin from Foreign Invested Firms Surveys conducted by China's Ministry of Commerce (MOC). We then merge the country of origin data with the NBS firm survey data, using firm names and other contact information.

\subsection{Identifying Managers' Gender}

Prejudice against women can be more profound at higher levels of a firm's hierarchy (Bertrand and Hallock, 2001). This is often referred to as the "glass ceiling" effect, which stops women from getting promoted to senior-level management positions (Nevill et al., 1990). Do cultural spillovers also affect firms' appointment of female managers? To answer this question, we need information on the gender information of the manager of each firm. Unfortunately, the NBS industrial firm survey dataset only provides the names of the legal representatives, not their gender. ${ }^{21}$ To get

\footnotetext{
${ }^{18}$ There are situations when the ID of the same firm changes over time, due possibly to restructuring or merger and acquisition. To resolve this data issue, we use a firm's name, sector, and address to complement the use of firm ID to identify the same firm over time.

${ }^{19}$ An alternative definition of skilled labor is college and above. Under this definition, skilled labor accounts for 9 percent of the total employment in 2004. Our results are robust to this alternative definition.

${ }^{20}$ Wage information by gender is available in China's annual urban household surveys, which we use to assess the potential labor supply effects (See Table A4 in the appendix and Section 4.1 for details).

${ }^{21}$ The NBS industrial firm surveys of 1998-2000 provide the job title of the "legal person representatives", in addition to their names. About $84 \%$ of firms listed their general managers (or chief executives) as legal person representatives.
} 
around this data limitation, we come up with a novel method to identify the gender of a firm's manager, based on the last character of the name of the legal representative in our data. ${ }^{22} \mathrm{We}$ use a $20 \%$ random sample of China's $1 \%$ population census in 2005, which contains 2.5 million names and their gender. For each Chinese character, we calculate the probability that it is used in a female name based on our name database, using the following formula: ${ }^{23}$

$$
\text { female_prob }{ }_{i}=\frac{\text { freq_female }_{i}}{{\text { freq_female } e_{i}+\text { freq_male }}_{i}},
$$

where freq_female $_{i}\left(\right.$ freq_male $\left._{i}\right)$ is the number of times that character $i$ appears as the last character in a female (male) name. Table A1 in the appendix lists the ten characters with the highest (lowest) female probability. For the top ten highest feminine characters, the probability that any of those characters is used in a male name is always less than $2 \%$.

\subsection{Country-Level Data}

To measure countries' gender culture, we use two data sources. The first data source, often used in studies on cross-country gender issues, is the Human Development Report published by the United Nations Development Program (UNDP) in 2012. ${ }^{24}$ The UNDP provides a set of indicators for gender inequality across 149 countries. In this study, we use the Gender Inequality Index (GII), which is a composite index capturing the loss of women's achievement due to gender biases. This index covers three aspects of a country's gender inequality, namely reproductive health, empowerment, and labor market participation. A higher GII indicates greater gender inequality. As Panel A of Table 1 shows, countries with the lowest GII are Sweden, Denmark, Netherlands, Norway and Switzerland. Countries with the highest GII include Saudi Arabia, India, UAE, Indonesia and Cambodia. Obviously, a country's GII is correlated with its income level, but there are rich countries with very high GII (such as Saudi Arabia) and poor countries with low GII (such as the Philippines). In the regression analysis below, we will always control for countries' income levels.

As a robustness check, we supplement the GII index with data from the World Value Survey (WVS), which provides subjective survey-based measures of gender-related perceptions and beliefs. We use the 2005 wave of WVS, which cover survey results for 53 countries. To construct our survey-based gender inequality index, we use the following three questions about women:

- Question V44 "Men should have more right to a job than women";

- Question V61 "On the whole, men make better political leaders than women do";

\footnotetext{
${ }^{22}$ A Chinese names usually starts with a last name, followed by a first name, which can have one or two characters. When a first name has two characters, the second character is more informative in terms of femininity or maculinity. That is why we only focus on the last character of Chinese names.

${ }^{23}$ We restrict our sample to people who aged between 35 and 65 in 2005.

${ }^{24}$ The reports have been published since 2008. We chose 2012 to maximize the coverage of countries.
} 
- Question V63: "Men make better business executives than women do".

There are three choices to answer Question V44: "agree", "neither" and "disagree". We calculate the individual score by assigning $0,0.5$ and 1 to these three choices, respectively. The country score of V44 is the average score over all individuals in that country. Questions V61 and V63 have four choices: "strongly agree", "agree", "disagree" and "strongly disagree". We assign 0, 0.33, 0.67 and 1 to these choices. We first compute each country's average V44, V61 and V63 scores, before using the simple mean across the three averages as a country's WVS index. A higher WVS index indicates lower gender inequality. Based on our calculation, Panel B of Table 1 shows that top 5 countries in terms of the WVS index are Sweden, Norway, France, Finland and Canada. Countries with the lowest WVS index are India, Iran, Malaysia, Indonesia and Vietnam. The GII and WVS indices are not available for three ethnic Chinese FDI sources - Hong Kong, Macau, and Taiwan. ${ }^{25}$ The cross-country correlation between WVS and GII indices is about -0.66.

\subsection{Industry-Level Data}

We use three main industry-level variables in the regression analysis: female labor intensity, the import-output ratio, and the Herfindahl index. The last two were computed and aggregated based on China's Customs transaction-level data and NBS industrial firm data, respectively. See Table A2 in the appendix for details.

The key industry-level measure is female labor intensity, which we obtained from Do, Levchenko and Raddatz (2016). The data are originally taken from a publication titled "Women in the Labor Force: A Databook" by the US Bureau of Labor Statistics (BLS). It contains information on total employment and the female share of employment in each 4-digit industry (262 categories) defined by the US Census's Current Population Survey, covering both manufacturing and non-manufacturing sectors. ${ }^{26}$ For each industry, we first take the average of the female labor shares across the sample years: 2004-2009. We then keep 77 manufacturing or mining sectors, and match each of them to a distinct NAICS 6-digit code (511 categories), using a concordance table available from the US Census website. Finally, we match a NAICS 6-digit code to a unique Chinese 4-digit industry code (CIC code), using a concordance table constructed by Ma, Tang and Zhang (2014). We then aggregate these measures up to the CIC 3 -digit level (166 categories). ${ }^{27}$

\footnotetext{
${ }^{25}$ Given that the major populations of the three economies are ethnic Chinese, who are highly adaptive to the local culture, their measures of gender norms, even when available, may not be reflected in their employment practices in China. Moreover, whether we should treat the ethnic Chinese investments as FDI is subject for debate. Regardless, the data limitation forces us to drop FIEs with major investor from the ethnic Chinese economies, which account for about $48 \%$ of the FIEs in the 2004 cross section.

${ }^{26}$ Industries are classified based on the U.S. Census 2007 classification.

${ }^{27}$ Our empirical results are insensitive to using female labor intensity measures at the 2-digit level (29 categories). The estimated welfare gain of the counterfactual exercise that eliminates gender biases across firms within a 2-digit sector will be slightly larger. Obviously, the cost of using measures at a more aggregate industry level is that in our quantitative analysis, imposing the same factor intensities for all firms within a broad industry requires stronger
} 
Table A3 in the appendix lists the top 10 and bottom 10 industries in terms of female labor intensity (comparative advantage). The industries with the highest female labor share are apparel (0.65), leather products (0.60), fur accessories (0.60). In contrast, those industries with the lowest female labor share are cement products $(0.103)$, cement (0.103), and steel smelting (0.131). These industries all appear to depend more on physically-demanding tasks.

\subsection{Summary Statistics of the Key Variables}

Table 2 reports the summary statistics of the key variables used in the analysis (see Table A2 in the appendix for definitions of all variables used in the paper). Out of the 250,000 firms, the average firm female labor share is 0.41 . Among the sub-sample of domestic Chinese firms (about $78 \%$ of the firm-year observations), the mean is 0.39, compared to 0.48 for FIEs (excluding Hong Kong, Macau and Taiwan's FIEs). FIEs also appear to be more likely to appoint women as managers. Of all firms for which the name of the manager (legal representative) can be identified, the proportion of all firms that have a female manager is 0.25 , compared to 0.24 for domestic firms and 0.26 for FIEs. Table 2 also reports the means and standard deviations for all variables used in the regressions, at the firm, industry and country levels.

Figure 1 plots the kernel density of female labor shares for both domestic firms and FIEs in 2004, showing that a significantly larger density of FIEs have a higher female-to-male labor ratio. To partially address the concern that FIEs are distributed unevenly across industries, due to differences in comparative advantages for instance, Figure 2 plots the kernel density of firms' female labor shares after demeaning them from their corresponding 4-digit industry averages. It confirms that the different distributions of female labor shares between domestic firms and FIEs are not driven by their varying prevalences across industries. ${ }^{28}$

\section{Empirical Evidence}

\subsection{Cultural Transfers within Multinational Firm Boundaries}

We first empirically examine Proposition 1, which is about the cultural transfers of multinational headquarters' gender norms to their affiliates in China. To this end, we estimate the following specification using the 2004 cross-sectional sample:

$$
\left(\frac{f}{f+m}\right)_{i c}=\beta_{0}+\beta_{1} G I I_{c}+\beta_{2} \ln (G D P / P o p)_{c}+\mathbf{X}_{i c}^{\prime} \gamma+\{F E\}+\varepsilon_{i c}
$$

assumptions. Since the original female labor intensity measures are available for 77 sectors, we think that the 3 -digit CIC level is the most appropriate level of aggregation.

${ }^{28}$ One can argue that even within a narrow industry, there is still a wide range of activities in which domestic and foreign firms may specialize differently. In the regression analysis below, we will control for a host of firm-level technology measures to deal with this potential within-industry variation. 
where $\left(\frac{f}{f+m}\right)_{i c}$ is the female share in employment of foreign firm $i$ from country of origin $c$, or the probability that it has a female manager. $G I I_{c}$ is the gender inequality index of country $c$, as described in Section 3. Country c's (log) GDP per capita, $\ln (G D P / P o p)_{c}$, is included as a regressor to control for any country-specific determinants of female employment that are related to the country's stage of development. The regression sample includes only FIEs. Thus, identification comes from the variation in the gender norms of the multinationals' countries of origin.

The regressor $\mathbf{X}_{i j}$ is a vector of firm-level controls we add based on the determinants of firms' female employment proposed in the literature. To the extent that investments in capital, technology, and automation in production reduce the demand for physically demanding tasks (Juhn, Ujhelyi, and Villegas-Sanchez, 2014), technology transfer from advanced economies and the associated investment by the affiliates may complement female labor. To address this concern, we include as controls a FIE's computer intensity, R\&D intensity, $\log$ (TFP) (measured by the Olley-Pakes method), skill intensity, and $\log$ (capital intensity) (see Table A2 in the appendix for definitions). We also control for the firm's wage rate and $\log$ (output). The former is to address the concern that FIEs may take advantage of the lower wages of female workers, due possibly to gender biases, and hire more of them. The latter is to take into account any positive effect of firm size on female employment. $^{29}$

FIEs may adapt to the local business culture over time. In the initial years of operation in China, a foreign firm may bring its home culture to the host country. Such cultural transfer, however, may dissipate over time if the affiliate assimilates itself with the local culture and behaves more like a domestic firm. We control for the potential assimilation effect by including the FIE's $\log ($ age $)$ as a regressor. Finally, we include province and 4-digit industry fixed effects in $\{F E\}$. Province fixed effects control for any time-invariant local-labor-market factors that affect foreign firms' employment decisions, as China's social and economic environments differ substantially across regions. Industry fixed effects control for any unobservable industry heterogeneity that may affect firms' female labor shares, such as an industry's female comparative advantage. $\varepsilon_{i c}$ is the error term.

The regression results reported in Table 3 provide strong support for Proposition 1. By controlling for province and 4-digit industry fixed effects but without any other firm covariates, we find in column 1 a negative and fairly significant (at the $5 \%$ level) correlation between multinationals' home countries' GII and their affiliate's female labor shares in China. In column 2, when a wide range of firm controls are included in addition to the fixed effects, the coefficient of GII becomes statistically significant at the $1 \%$ level. The estimated coefficient of -0.099 implies that a one-standard-deviation decrease in a country's GII (0.195, equivalent to changing Malaysia's GII

\footnotetext{
${ }^{29}$ For instance, if a larger firm requires more management inputs, and women have a comparative advantage in communication and management skills, then we should expect a positive correlation between a firm's size and its female employment share, something that our regression results confirm.
} 
to the level of Germany) is associated with a 1.9 percentage-point higher female labor share in that country's affiliates in China. We find no evidence that the income level of the country of origin is related to its foreign affiliates' female employment. Firms' computer intensity, R\&D intensity, and TFP are all negatively correlated with their female labor shares. In other words, our results show that among FIEs in China, technology does not appear to complement firms' female employment. Older FIEs hire proportionately more women on average, rejecting the assimilation hypothesis in this context.

Column 3 uses the World Value Survey (WVS) index as a country's measure of gender norms. The positive and statistically significant coefficient on the WVS index supports Proposition 1, as a higher WVS index implies a more positive attitude towards women. Columns 4 and 5 use the share of female workers in a firm's low-skilled and high-skilled employment as the dependent variable, respectively. We find that while the female labor shares in a country's foreign affiliates are negatively related to the country's gender inequality for both types of workers, the relationship is more pronounced among low-skilled workers. Column 6 uses the probability of the firm's having a female manager, as defined in Section 3.2, as the dependent variable. The reported negative and significant correlation between a FIE's GII and the likelihood that the firm appoints a female manager also supports Proposition 1.

In column 7, we add in the regression an interaction term between an industry's female labor intensity, measured using the U.S. data as described in Section 3.4, and the FIE's source country's GII. The coefficient on the stand-alone GII becomes insignificant, while the coefficient on the interaction term is negative and statistically significant, supporting the second part of Proposition 2 that the cultural transfers from multinationals are stronger in female labor-intensive industries. In sum, the results in Table 3 suggest that multinationals' cultural transfers are not a general feature of FDI. The culture of the country of origin matters.

One may argue that the reason why FIEs employ more women than domestic firms is because of their intention to exploit the lower equilibrium wages of women, possibly due to gender discrimination in the labor markets (Siegel, Kodama, and Halaburda, 2014). Another alternative hypothesis is that women are attracted to move to locations where there are more foreign firms, which are on average less biased against women. Notice that either hypothesis implies a negative correlation between average female wages and the prevalence of FIEs across markets. Without information on wages by gender in the firm data, we rely on China's urban household survey data for 2004-2007 instead to examine whether our results on cultural transfers are driven by either of the hypotheses. Table A4 in the appendix reports the regression results, showing a positive correlation between the female wage premium and FIEs' output share across cities, after controlling for obvious determinants of wages. While these results imply no causality, they confirm that FIEs do not seem to be attracted to markets where female wages were lower, or that they depress female wages. 


\subsection{Firms' Female Labor Shares and Profits}

Next we empirically examine Proposition 2 that predicts a positive relationship between a firm's profit and its female labor share. To this end, we regress a firm's profitability, defined as the ratio of profit to sales, on its female labor share, using the 2004-2007 panel data. ${ }^{30}$ As Table 4 reports, we find a positive and statistically significant correlation between a firm's female labor share and profitability. Such result is obtained after controlling for firm and year fixed effects, as well as firmlevel controls ( $R \& D$ intensity, capital intensity, log wage rate, log firm age, and log employment as in Table 3) in column $1,{ }^{31}$ and when we restrict the sample to only domestic firms in column 2 .

In columns 3 and 4, we add in the regressions an interaction term between an industry's female labor intensity, measured using U.S. data, and the firm's female labor share as variable of interest. The positive and statistically significant coefficient on the interaction terms estimated using both the entire and domestic firm samples supports Proposition 2 that a firm's loss in profits, due to gender biases, is stronger in female labor-intensive industries.

\subsection{Cultural Spillovers from Multinationals to Domestic Firms}

In this section we examine whether domestic firms' employment decisions can be influenced by FIEs. We adopt the empirical specification widely used in the literature on FDI spillovers (e.g., Aitken and Harrison, 1997; Javorcik, 2004), to explore the relationship between the prevalence of FDI and domestic firms' outcomes in the same market, defined as either an industry or a city. ${ }^{32}$ The specification for estimating cultural spillovers is

$$
\left(\frac{f}{f+m}\right)_{i k}=\gamma_{0}+\gamma_{1} F D I_{k}+\gamma_{2} \text { import }_{k}+\gamma_{3} \operatorname{Herf}_{k}+\mathbf{X}_{i k}^{\prime} \gamma+\{F E\}+\varepsilon_{i k}
$$

where $\left(\frac{f}{f+m}\right)_{i k}$ is either the female labor share or the probability of having a female manager of domestic firm $i$ operating in market $k . F D I_{k}$, import $_{k}$, and $H e r f_{k}$ are market $k$ 's output share of FIEs, import-to-output ratio, and Herfindahl index, respectively. ${ }^{33}$ We include an industry's import-to-output ratio as a regressor to control for the possibility that import competition may reduce gender inequality by pushing the more discriminating firms to exit (Black and Brainerd, 2004). For the same reason, we also control for an industry's Herfindahl index to control for any changes in market structure, possibly due to an increased prevalence of FIEs. To the extent that

\footnotetext{
${ }^{30}$ We use the firm's profit-sales ratio rather than $\log$ (profit) as the dependent variable as there are many negative values for profits in the data.

${ }^{31}$ We replace $\ln$ (output) by $\ln$ (employment) for this analysis as obviously, revenue and output are strongly correlated. As the goal is to control for the scale effect on profits (and female labor shares in the previous tables), using $\ln$ (employment) is a compromise. All results in this table remain robust when $\ln$ (output) is used as a control. The t-statistics of $\ln$ (output), if included, is very high. Results are available upon request.

${ }^{32}$ There are 345 prefecture-level cities in China.

${ }^{33}$ The HS 8-digit product level import data come from Chinese Customs, which we further aggregate into 4-digit industry level.
} 
these measures capture the changes in the degree of market competition, any identified effect of FDI on firms' female labor shares should be above and beyond the standard competition effect. ${ }^{34}$

As often emphasized in the literature on FDI, domestic firms learn from FIEs about product designs, production technology, and foreign sales opportunities. These spillovers can be gender-biased. For instance, technology upgrading can increase the demand for female labor (Juhn, Ujhelyi, and Villegas-Sanchez, 2014). To partially control for the technology-induced effect on firms' employment, we include in the regressions various measures of technology, $\mathbf{X}_{i k}$, as we did in Table 3 . $\{F E\}$ includes a host of fixed effects, which will be explained below.

We estimate eq. (15) using a sample of domestic firms only. We first report in Table 5 the regression results with markets defined as 4-digit industries, before reporting in Table 6 the results with markets defined as cities. Based on the 2004 sample, column 1 of Table 5 reports that domestic firms' female labor shares are increasing on average with the share of output by FIEs in the same industry. We also find a negative coefficient on the Herfindahl index, consistent with Becker's (1957) hypothesis that competition reduces employers' discrimination. However, the negative correlation between the import-output ratio and domestic firms' female labor shares across industries cannot be explained by the same hypothesis. In column 2, we find that the probability of a domestic firm's having a female manager is positively correlated with the output share of FIEs across industries. ${ }^{35}$ In particular, controlling for province fixed effects and a host of firm covariates, we find that a one standard-deviation increase in the FIEs' share in an industry's output (0.218; see Table 2) is associated with a 1.02 percentage-point increase in the likelihood that a domestic firm appoints a female manager.

One may be concerned that the positive correlation between domestic firms' female labor shares and FIEs' output shares across industries is simply a reflection of FIEs' self-selecting into industries in which women have a comparative advantage. To address this concern, from columns 3 to 7 , we use the 2004-2007 panel data so that firm fixed effects can be included to explore a firm's potential response to the changes in FIEs' prevalence in the same market. According to the results reported in column 3, domestic firms' female labor shares are positively correlated with FIEs' output share across industries, even after controlling for firm and year fixed effects. The correlation is economically significant - a one standard-deviation increase in FIEs' share in an industry's output is associated with an average 0.7 percentage-point higher female labor share among domestic firms in the same industry.

In columns 4 to 5, we examine whether FDI from countries with lower gender inequality generates a larger spillover effect. In addition to the stand-alone output share by FIEs in the industry,

\footnotetext{
${ }^{34}$ Notice that it is difficult to quantitatively separate the competition effect from the cultural effect.

${ }^{35}$ Since the managers (legal representative) of firms were not changed frequently between 2004 and 2007 , we do not have enough variation to identify the potential positive correlation using the panel data after controlling for firm fixed effects. As a result, when the probability of the firm's having a female manager is used as the dependent variable, we use the 2004 cross-sectional sample for the analysis.
} 
we include an interaction term between FIEs' output share and the average measure of their gender norms, measured by either output-weighted average $G I I$ or $W V S$ index. We find statistically significant coefficients with the expected signs on the interaction terms in columns 4 and 5 . In sum, the cultural spillovers from FIEs documented so far appear to be mainly coming from multinationals whose home countries' culture is more favorable for women, supporting Proposition 4.

In column 6, we add an interaction term between the prevalence of FDI and the (U.S.) female labor intensity of the industry. We find that the cultural spillovers of gender norms are stronger in industries in which women have a comparative advantage. In column 7 , when we include a triple interaction term between the industry's prevalence of FDI, average GII of FIEs, and female comparative advantage, we find that the spillover effect is stronger from low-GII FIEs, particularly in the more female labor-intensive industries, as predicted by Proposition 5.

We conduct two robustness checks. First, we measure the prevalence of FIEs by their employment share in the same industry to address the concern that the degree of spillovers is proportional to FIEs' employment rather than their sales. Second, we use the lagged FIEs' share of output in the same industry to partially address the usual simultaneity bias. The regression results remain robust to using these alternative measures, as reported in Table A5 and A6 in the appendix.

In Table 6, we measure the prevalence of FDI by the FIEs' output share in a city, instead of an industry. Similar to the results at the industry level reported in Table 5, we find that both domestic firms' female labor shares and probabilities of appointing female managers are positively correlated with FIEs' output share across cities, after controlling for firm and year fixed effects, as well as the average industries' import-to-output ratios and Herfindahl indices. Specifically, the coefficient of 0.092 in column 3 implies that a one standard-deviation increase in the foreign output share in the same city ( 0.182 ; see Table 2$)$ is associated with an average 1.7 percentage-point increase in a domestic firm's female labor share.

Two remarks are in order before we conclude this section. In both Tables 5 and 6 , if only the competitive pressure of FIEs matters, we would not be able to find a significant coefficient on the interaction term between FIEs' output share and their average home country's gender norms. Moreover, firms in the same city but different industries are unlikely to be competitors in the same final-goods market. Many FIEs in China are also export-oriented. The spillover effect from FIEs to domestic firms in the same city is unlikely to be all due to increased competition from FIEs. ${ }^{36}$

\footnotetext{
${ }^{36}$ The entry of foreign firms into a market may drive up input costs but lower final goods prices. In our model with heterogeneous firm productivity and discrimination factors, the more discriminating firms, due to resulting losses, are more likely to exit the market. We find in our data that firms with higher female labor shares are less likely to exit in response to an increase in FDI in the same market, supporting Becker's (1957) seminal hypothesis. Such adjustments raise firms' profits but more importantly, reduce the misallocation of resources at the industry and national levels, therefore raising aggregate efficiency. These regression results are available upon request.
} 


\section{Quantifying the Effects of Firms' Gender Discrimination on Ag- gregate TFP}

In this section, we use the model developed in Section 2 to quantify the aggregate productivity loss due to gender discrimination and the productivity gain associated with FDI's cultural spillovers in China.

\subsection{Quantifying the Productivity Loss due to Gender Discrimination}

To account for the common sources of misallocation studied in the literature (i.e., capital and output distortions), we extend a firm's production function in Section 2 to one that also has capital as a factor of production:

$$
y_{i j}=\varphi_{i} \mu_{j}\left(f_{i j}^{\beta_{j}} m_{i j}^{1-\beta_{j}}\right)^{\alpha_{j}} k_{i j}^{1-\alpha_{j}}
$$

where $y_{i j}$ and $k_{i j}$ stand for value added (after intermediate inputs are subtracted) and capital of firm $i$ in industry $j$, respectively. $\alpha_{j}$ and $\beta_{j}$ are industry $j$ 's cost shares of labor and capital in production.

For each unit of capital purchased, a firm pays $\left(1+\tau_{K i}\right) r$, where $\tau_{K i}$ is a firm-specific capital distortion. Output distortion is modeled as a revenue tax (i.e., for each unit of value added created, a firm receives only a fraction $1-\tau_{Y i}$ of it).

We first focus on quantifying the efficiency loss due to resource misallocation in each industry. Based on the average revenue product (ARP) approach to studying resource misallocation, various firm-specific unobservable distortions can be measured by their empirical counterparts as follows: ${ }^{37}$

$$
\begin{aligned}
1+\tau_{K i} & =\frac{1-\alpha_{j}}{\alpha_{j}\left(1-\beta_{j}\right)} \frac{w_{m} m_{i}}{r k_{i}} \\
1-\tau_{Y i} & =\frac{1}{\eta_{j} \alpha_{j}\left(1-\beta_{j}\right)} \frac{w_{m} m_{i}}{R_{i}} \\
1+\gamma_{i} & =\frac{\beta_{j}}{1-\beta_{j}} \frac{w_{m} m_{i}}{w_{f} f_{i}}
\end{aligned}
$$

According to HK, a firm's TFPR is proportional to the product of various wedges. By incorporating gender discrimination, together with output and capital distortions, eq. (18) for a firm's TFPR now becomes

$$
T F P R_{i}=\frac{w_{m}^{\alpha_{j}\left(1-\beta_{j}\right)}\left[\left(1+\gamma_{i}\right) w_{f}\right]^{\alpha_{j} \beta_{j}}\left[\left(1+\tau_{K i}\right) r\right]^{1-\alpha_{j}}}{\eta_{j}\left(1-\tau_{Y i}\right) \Lambda_{j}}
$$

where $\Lambda_{j} \equiv \alpha_{j}^{\alpha_{j}}\left(1-\alpha_{j}\right)^{1-\alpha_{j}} \beta_{j}^{\alpha_{j} \beta_{j}}\left(1-\beta_{j}\right)^{\alpha_{j}\left(1-\beta_{j}\right)}$.

\footnotetext{
${ }^{37}$ See Section 3.1 for the details of each firm-level variable used to compute firm-level wedges. Following HK, we drop 1 percent of the tails of the distributions of $\log \left(1+\tau_{K i}\right), \log \left(1-\tau_{Y i}\right)$, and $\log \left(1+\gamma_{i}\right)$, respectively.
} 
We can quantify the productivity loss due to gender discrimination in industry $j$ using the formula from HK as

$$
T F P_{j}=\left[\sum_{i=1}^{N_{j}}\left(\varphi_{i} \frac{\overline{T F P R}_{j}}{T F P R_{i}}\right)^{\sigma_{j}-1}\right]^{\frac{1}{\sigma_{j}-1}}
$$

where $\varphi_{i}$ is firm $i$ 's TFP, $\overline{T F P R}_{j}$ is the weighted average of $T F P R_{i}$, with weights equal to each firm's value added.

We implement the following procedures to compute a firm's TFP and TFPR.

1. We first compute a firm's $\gamma_{i}$ according to (18)

$$
\gamma_{i}=\frac{\beta_{j}}{1-\beta_{j}} \frac{w_{m} m_{i}}{w_{f} f_{i}}-1
$$

We set $w_{f} / w_{m}=0.78$, according to the average wage premium for men reported in China's statistical yearbooks for the sample period (2004-2007). We set $\beta_{j}$ for 166 3-digit (CIC) industries based on the female labor shares for 77 manufacturing industries in the U.S., using data from the U.S. Population Census (see Section 3.4 and Table A3 in the appendix for details).

2. We obtain capital cost shares, $1-\alpha_{j}$, at the NAICS 6 -digit level from the NBER-CES Manufacturing Industry Database. We use the concordance table and rules described in Section 3.4 to average them up to the 1663 -digit CIC industries. Since our industry classification is broader than that of HK (who consider over 4004 -digit industries), we impose $\sigma=2$, instead of 3 as they did. ${ }^{38}$ We then compute $1+\tau_{K i}$ and $1-\tau_{Y i}$ based on (16) and (17), using these industry-level parameters and firm-level data on employment and capital costs.

3. We then compute TFPR $R_{i}$ using estimated $\gamma_{i}, 1+\tau_{K i}, 1+\gamma_{i}$, as well as the aforementioned industry-level parameters, based on (19).

4. Finally, we compute firm $i$ 's TFP, based on the isoelastic demand curve described in Section 2.1 , as

$$
\varphi_{i}=\kappa_{j} \frac{R_{i}^{\frac{\sigma}{\sigma-1}}}{\left(f_{i}^{\beta_{j}} m_{i}^{1-\beta_{j}}\right)^{\alpha_{j}} k_{i}^{1-\alpha_{j}}},
$$

where $\kappa_{j}$ is a constant, independent of misallocation or discrimination. It will drop out when we compute the ratio of distorted to efficient TFP for each industry.

With all the components required to compute $T F P_{j}$ according to (20) in hand, we conduct three counterfactual exercises. In the first exercise, we compute the ratio of an industry's TFP

\footnotetext{
${ }^{38}$ Imposing $\sigma=3$ for each 3-digit industry will increase the estimated manufacturing TFP gains associated with removing all distortions by an order of magnitude larger than what HK find for China.
} 
with all three types of distortions present to its efficient level (with firms' TFPRs equalized within the same industry), as follows:

$$
\frac{T F P_{j}}{T F P_{j}^{e}}=\left[\sum_{i=1}^{N_{j}}\left(\frac{\varphi_{i}}{\bar{\varphi}_{j}} \frac{\overline{T F P R}_{j}}{T F P R_{i}}\right)^{\sigma_{j}-1}\right]^{\frac{1}{\sigma_{j}-1}}
$$

where $\bar{\varphi}_{j}=\left[\sum_{i=1}^{N_{j}} \varphi_{i}^{\sigma_{j}-1}\right]^{\frac{1}{\sigma_{j}-1}} \cdot 39$ In the second exercise, we want to gauge the contribution of gender discrimination to an industry's efficiency loss. Therefore, we compute the ratio of the industry's TFP with output and capital distortions (but without gender distortions) to the efficient level of TFP, as follows:

$$
\frac{T F P_{j}^{\gamma=0}}{T F P_{j}^{e}}=\left[\sum_{i=1}^{N_{j}}\left(\frac{\varphi_{i}}{\bar{\varphi}_{j}} \frac{\overline{T F P R}_{j}^{\gamma=0}}{\operatorname{TFPR}_{i}^{\gamma=0}}\right)^{\sigma_{j}-1}\right]^{\frac{1}{\sigma_{j}-1}}
$$

In the third exercise, we are interested in knowing the contribution of capital distortions to an industry's efficiency loss. The purpose of this exercise is to compare the contribution of gender discrimination with the main source of distortion studied in the literature. To this end, we compute the ratio of TFP with the presence of both output and gender distortions (but without capital distortions) to the efficient level of TFP:

$$
\frac{T F P_{j}^{\tau_{K}}=0}{T F P_{j}^{e}}=\left[\sum_{i=1}^{N_{j}}\left(\frac{\varphi_{i}}{\bar{\varphi}_{j}} \frac{\overline{T F P R}_{j}^{\tau_{K}=0}}{T F P R_{i}^{\tau_{K}=0}}\right)^{\sigma_{j}-1}\right]^{\frac{1}{\sigma_{j}-1}}
$$

For each of the three scenarios, we then compute the corresponding ratios for the economy's manufacturing TFP in each year using the Cobb-Douglas aggregate: $\frac{T F P}{T F P^{e}}=\prod_{j=1}^{J}\left(\frac{T F P_{j}}{T F P_{j}^{e}}\right)^{\theta_{j}}$, where $\theta_{j}$ is industry $j$ 's value added share in the manufacturing sector.

Table 7 reports for each sample year the TFP gains $\left(100 \times\left(\frac{T F P^{e}}{T F P}-1\right)\right)$ by removing all three distortions, capital and output distortions, as well as gender and output distortions, respectively. Using formula (21)-(23), column 1 shows that removing all three types of distortions will bring about $100 \%$ and $96 \%$ aggregate TFP gains in 2004 and 2007, respectively. The gradual decline in the TFP gain reflects that the Chinese manufacturing sector has become more efficient over time. Column 2 shows that by eliminating capital and output distortions (keeping gender discrimination), the estimated TFP gain for the two years decline to about $95 \%$ and $91 \%$, respectively. In other words, as reported in column 4, gender discrimination accounted for about $5 \%$ China's aggregate TFP loss during the sample period.

\footnotetext{
${ }^{39}$ Following HK, we drop 1 percent of the tails of the distributions of $\log \left(T F P R_{i} / \overline{T F P R}{ }_{j}\right)$ and $\log \left(N_{j}^{\frac{1}{\sigma_{j}-1}} \varphi_{i} / \bar{\varphi}_{j}\right)$, respectively. We recalculate all the industries' averages after removing those outliers in the sample.
} 
As a comparison, we report the associated TFP gain with output distortion and gender discrimination removed, keeping capital distortions. The resulting TFP gain is reduced significantly. As reported in column 5, capital distortions accounted for $29-34 \%$ of aggregate TFP loss during the sample period, about 6 times the productivity cost of gender discrimination.

\subsection{Quantifying the Productivity Gain from Multinationals' Cultural Spillovers}

We now quantify the contribution of the cultural effect of FDI. Recall that our model shows that when facing FIEs from countries with lower mean and variance of $\log (1+\gamma)$, domestic firms' Bayesian updating will result in a gradual reduction in the mean and the variance of their own $\log (1+\gamma)$. While the mean does not affect an industry's TFP based on the APR approach, a lower variance, according to (7), will imply a higher industry TFP. ${ }^{40}$

To show that the prevalence of FDI in an industry is related to the dispersion of $\log (1+\gamma)$, we regress the change in the standard deviation of the firms' estimated $\log (1+\gamma)$ on the change in the FIEs' share in a sector's output. We run these regressions over one, two, and three-year horizons, respectively. As reported in Table 8, there is a negative correlation between the two variables, with the correlation being statistically significant for the samples over the two- and three-year horizons. The lack of significance in the regression results based on a sample at the annual frequency may imply that learning takes more than a year to be realized. Figure 3 illustrates a negative relationship between the change in the dispersion of firm $\ln (1+\gamma)$ and the change in the FIEs' output share between 2004 and 2007 across 3-digit industries.

Through the lens of our model, we can ask: what would happen to gender inequality and the associated TFP losses if the share of FDI in a sector was reduced to zero or by half in China during the sample period? Answering such question involves several simple steps of calculation. First, we know that based on the coefficient of -0.929 in column 3 of Table 8, if the average FIEs' output share was reduced from the sectoral average of $34 \%$ to $17 \%$ (half) and 0 , respectively, the associated increase in the standard deviation of $\log (1+\gamma)$ will be around 0.16 and $0.32 .{ }^{41}$ Given that the average standard deviation of $\log (1+\gamma)$ of a sector over the sample period (2004-2007) is about 1.67, such increases in dispersion of $\log (1+\gamma)$ are about $9.6 \%$ and $19.2 \%$ of the observed dispersions during the sample period, which will also be their respective contributions to the potential TFP loss due to gender discrimination. ${ }^{42}$ In other words, the cultural spillover effect contributes about $1 \%$ (i.e., $19 \%$ of $5 \%$ ) aggregate TFP gains during the sample period.

\footnotetext{
${ }^{40}$ With firms' endogenous entry and exit, the conditional mean of $\ln (1+\gamma)$ will be different between the efficient and distorted TFP. Thus, the changing mean of $\ln (1+\gamma)$ due to cultural spillovers will also matter.

${ }^{41}$ These numbers are obtained by computing $(-0.929) \times(-0.34) \approx 0.33$ and $(-0.929) \times(-0.17) \approx 0.16$, respectively.

${ }^{42}$ These numbers are obtained by computing $0.32 / 1.67$ and $0.16 / 1.67$ respectively.
} 


\section{Concluding Remarks}

This paper studies empirically whether and how multinational firms transmit culture across countries, by focusing on gender norms. Using Chinese manufacturing firm data over the period of 2004-2007, we find that foreign affiliates whose home countries' culture is more gender-equal tend to hire proportionately more women and appoint female managers. Foreign firms, especially those from countries with a more gender-equal culture, also generate cultural spillovers to domestic firms, as revealed by a positive correlation between domestic firms' female labor shares and the prevalence of FDI across industries or cities. Our empirical results remain robust even after we control for firm fixed effects, as well as a wide range of time-varying firm characteristics.

To discipline our empirical analysis and quantify the aggregate efficiency loss associated with gender discrimination and the cultural effects of FDI, we build a parsimonious multi-sector taskbased model that features firm heterogeneity in productivity and biases towards female workers, as well as women having a comparative advantage in skill- rather than physically-intensive tasks. Consistent with the model predictions, we find evidence that domestic firms respond to increased FDI by employing more women, likely due to imitation. Such cultural spillovers are stronger in the more female labor-intensive industries. We also find that discriminating firms sacrifice profits.

Through the lens of our model, we quantify the aggregate TFP loss due to discrimination against women, and how much FDI has alleviated that in China. Eliminating gender discrimination altogether is associated with about $5 \%$ increase in aggregate manufacturing TFP. The cultural effect of FDI, through improving gender norms, is estimated to have contributed about $1 \%$ increase in aggregate manufacturing TFP. Our results reveal an under-explored externality of FDI, in addition to technology spillovers which have been the focus of the literature. More generally, this paper

highlights how globalization can overturn the long-standing prejudice against women in a country. 


\section{References}

[1] Acemoglu, Daron, and David Autor (2011) "Skills, Tasks and Technologies: Implications for Employment and Earnings" Handbook of Labor Economics, Vol.4, pp. 1043-1171.

[2] Aitken, Brian, and Ann Harrison (1997) "Do Domestic Firms Benefit from Direct Foreign Investment? Evidence from Venezuela" American Economic Review, 89(3), pp. 605-618.

[3] Alesina, Alberto, Paola Giuliano, and Nathan Nunn (2013) "On the Origins of Gender Roles: Women and the Plough" Quarterly Journal of Economics, 128(2), pp. 469-530.

[4] Alfaro, Laura (2016) "Gains from Foreign Direct Investment: Macro and Micro Approaches" forthcoming, World Bank Economic Review.

[5] Altonji, Joseph, and Rebecca Blank (1999) "Race and Gender in the Labor Market" in Orley Ashenfelter and David Card, eds., Handbook of Labor Economics, Vol.3C. Amsterdam: Elsevier.

[6] Arrow, Kenneth (1973) "The Theory of Discrimination" in Orley C. Ashenfelter and Albert Rees (eds.), Discrimination in Labor Markets, Princeton University Press.

[7] Becker, Gary (1957) The Economics of Discrimination, University of Chicago Press.

[8] Bertrand, Marianne (2011) "New Perspectives on Gender", Orley Ashenfelter and David Card eds, Handbook of Labor Economics, Vol. 4B, pp. 1545-1592.

[9] Bertrand, Marianne, and Kevin F. Hallock (2001) "The Gender Gap in Top Corporate Jobs" Industrial and Labor Relations Review 55(1), pp. 3-21.

[10] Bertrand, Marianne, and Sendhil Mullainathan (2004) "Are Emily and Greg More Employable than Lakisha and Jamal? A Field Experiment on Labor Market Discrimination" American Economic Review, 94(4), pp. 991-1013.

[11] Bisin, Alberto, and Thierry Verdier (2000) "Beyond The Melting Pot: Cultural Transmission, Marriage, And The Evolution Of Ethnic And Religious Traits" 113(3), Quarterly Journal of Economics, pp. 955-988.

[12] Bisin, Alberto, and Thierry Verdier (2011) "The Economics of Cultural Transmission and Socialization" Handbook of Social Economics, Vol.1, Ed by Jess Benhabib, Alberto Bisin and Matthew Jackson, North-Holland, pp. 339-416.

[13] Branstetter, Lee (2006) "Is Foreign Direct Investment a Channel of Knowledge Spillovers? Evidence from Japan's FDI in the United States" Journal of International Economics, 68(2), pp. 325-344.

[14] Black, Sandra, and Elizabeth Brainerd (2004) "Importing Equality? The Effects of Globalization on Gender Discrimination" Industrial and Labor Relations Review, 57(4), pp. 540-559.

[15] Borjas, George, and Valerie Ramey (1995) "Foreign Competition, Market Power, and Wage Inequality" Quarterly Journal of Economics, 110 (4), pp. 1075-1110.

[16] Brandt, Loren, Jo Van Biesebroeck, and Yifan Zhang (2012) "Creative Accounting or Creative Destruction? Firm-Level Productivity Growth in Chinese Manufacturing" Journal of Development Economics, 97(2), pp. 339-351.

[17] Cai, Fang, Yaohui Zhao, and Albert Park (2008) "The Chinese Labor Market in the Reform Era" in Loren Brandt and Thomas Rawski, eds., China's Great Economic Transformation: Origins, Mechanism, and Consequences, Cambridge University Press.

[18] Cavalcanti, Tiago, and Jose Tavares (2016) "The Output Cost of Gender Discrimination: a Model-Based Macroeconomic Estimate" Economic Journal, 126(590), pp. 109-134. 
[19] DeGroot, Morris H. (2004) Optimal Statistical Decisions, John Wiley \& Sons, Inc.

[20] Do, Quy-Toan, Andrei Levchenko, and Claudio Raddatz (2016) "Comparative Advantage, International Trade, and Fertility" Journal of Development Economics, 119, pp. 48-66.

[21] Duflo, Esther (2012) "Women's Empowerment and Economic Development" Journal of Economic Literature, 50(4), pp. 1051-1179.

[22] Fang, Hanming, and Andrea Moro (2010) "Theories of Statistical Discrimination and Affirmative Action: A Survey" Handbook of Social Economics, Vol.IA, edited by Jess Benhabib, Alberto Bisin, and Matthew Jackson, North-Holland, pp. 133-200.

[23] Fernandez, Raquel (2013) "Cultural Change as Learning: The Evolution of Female Labor Force Participation Over a Century" American Economic Review, 103(1), 472-500.

[24] Fernandez, Raquel (2011) "Does Culture Matter?" in J. Benhabib, M.O. Jackson, and A. Bisin, editors, Handbook of Social Economics, Vol. 1A, North Holland.

[25] Fisman, Ray, and Edward Miguel (2007) "Corruption, Norms, and Legal Enforcement: Evidence from Diplomatic Parking Tickets" Journal of Political Economy, 115(6), pp. 1020-1048.

[26] Friedman, Thomas (1999) The Lexus and the Olive Tree: Understanding Globalization, Picador.

[27] Gorodnichenko, Yuriy, and Gerald Roland (2016) "Culture, Institutions and the Wealth of Nations" forthcoming Review of Economics and Statistics.

[28] Guiso, Luigi, Paola Sapienza, and Luigi Zingales (2006) "Does Culture Affect Economic Outcomes?" Journal of Economic Perspectives, 20(2), pp. 23-48.

[29] Guiso, Luigi, Paola Sapienza, and Luigi Zingales (2009) "Cultural Biases in Economic Exchange?" Quarterly Journal of Economics (2009) 124 (3): 1095-1131.

[30] Harrison, Ann, and Andres Rodriguez-Clare (2010) "Trade, Foreign Investment, and Industrial Policy" Handbook of Development Economics Vol.5, edited by Dani Rodrik and Mark Rosenzweig.

[31] Hofstede, Geert (1980) Culture's Consequences: International Differences in Work-Related Values, Sage Publications.

[32] Hsieh, Chang-Tai, and Peter Klenow (2009) "Misallocation and Manufacturing TFP in China and India" Quarterly Journal of Economics, 124(4), pp. 1403-1448.

[33] Hsieh, Chang-Tai, Erik Hurst, Chad Jones, and Peter Klenow (2016) "The Allocation of Talent and U.S Economic Growth" NBER Working Paper \#18693.

[34] Hopper, Paul (2007) Understanding Cultural Globalization, Polity.

[35] Huntington, Samuel P. (1996) The Clash of Civilizations and the Remaking of World Order, Simon \& Schuster.

[36] Javorcik, Beata Smarzynska (2004) "Does Foreign Direct Investment Increase the Productivity of Domestic Firms? In Search of Spillovers Through Backward Linkages" American Economic Review, 94(3), pp. 605-627.

[37] Jayachandran, Seema (2015) "The Roots of Gender Inequality in Developing Countries" $A n$ nual Review of Economics, 7, pp. 63-88.

[38] Jovanovic, Boyan (1982) "Selection and the Evolution of Industry" Econometrica, 50(3), pp. 649-670. 
[39] Juhn, Chinhui, Gergely Ujhelyi, and Carolina Villegas-Sanchez (2014) "Men, Women, and Machines: How Trade Impacts Gender Inequality" Journal of Development Economics,106, pp. 179-193.

[40] Kawaguchi, Daiji (2007) "A Market Test for Sex Discrimination: Evidence from Japanese Panel Data" International Journal of Industrial Organization, 25(3), pp. 441-460.

[41] Keller, Wolfgang, and Stephen Yeaple (2009) "Multinational Enterprises, International Trade, and Productivity Growth: Firm-level Evidence from the United States" Review of Economics and Statistics, 91(4), pp. 821-831.

[42] Kodama, Naomi, Beata S. Javorcik, and Yukiko Abe (2016) "Transplanting Corporate Culture across International Borders: FDI and female employment in Japan". Research Institute of Economy, Trade and Industry (RIETI) Working Paper.

[43] Ma, Yue, Heiwai Tang, and Yifan Zhang (2014). "Factor Intensity, Product Switching, and Productivity: Evidence from Chinese Exporters" Journal of International Economics, 92(2), pp. 349-362.

[44] Maystrea, Nicolas, Jacques Olivier, Mathias Thoenig, and Thierry Verdier (2014) "ProductBased Cultural Change: Is the Village Global?" Journal of International Economics, 92(2), pp. 212-230.

[45] McKinsey Global Institute (2015) “The Power of Parity: How Advancing Women's Equality Can Add $\$ 12$ Trillion to Global Growth."

[46] Melitz, Marc (2003) "The Impact of Trade on Intra-Industry Reallocations and Aggregate Industry Productivity" Econometrica, 71(6), pp. 1695-1725.

[47] Nevill, Ginny, Alice Pennicott, Joanna Williams, and Ann Worrall (1990) Women in the Workforce: The Effect of Demographic Changes in the 1990s. London: The Industrial Society.

[48] Phelps, Edmund S. (1972) "The Statistical Theory of Racism and Sexism" American Economic Review, 62(4), pp. 659-661.

[49] Pieterse, Jan Nederveen (2003) Globalization and Culture: Global Melange. Rowman \& Littlefield Publishers.

[50] Pitt, Mark, Mark Rosenzweig, and Mohammad Nazmul Hassan (2012) "Human Capital Investment and the Gender Division of Labor in a Brawn-Based Economy" American Economic Review, 102(7), pp. 3531-3560.

[51] Restuccia, Diego, and Richard Rogerson (2013) "Misallocation and Productivity" Review of Economic Dynamics, 16(1), pp. 1-10.

[52] Roland, Gerard (2004) "Understanding Institutional Change: Fast-Moving and Slow-Moving Institutions" Studies in Comparative International Development, 38(4), pp. 109-131.

[53] Siegel, Jordan, Naomi Kodama, and Hanna Halaburda (2014) "The Unfairness Trap: A Key Missing Factor in the Economic Theory of Discrimination" Harvard University Working Paper.

[54] Wei, Shang-Jin, and Xiaobo Zhang (2011) "The Competitive Saving Motive: Evidence from Rising Sex Ratios and Savings Rates in China" Journal of Political Economy, 119(3), pp. 511-564. 
Figure 1: Distribution of Firms' Female Labor Share (2004)

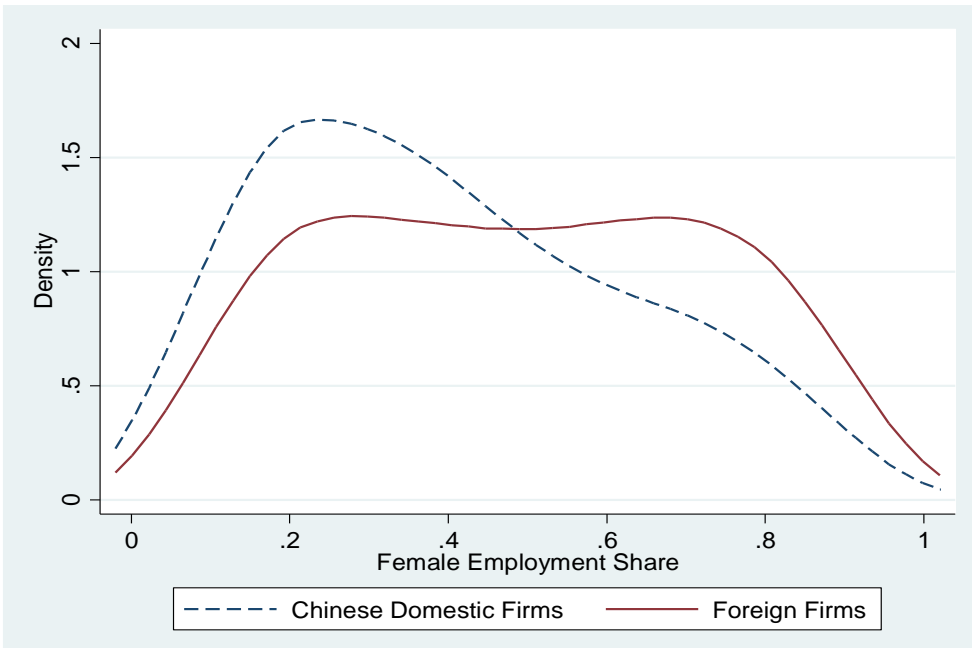

Source: NBS annual survey of industrial firms (2004) and authors' calculation

Figure 2: Distribution of Firms' Female Labor Share (2004) (controlling for 4-digit Industry Fixed Effects)

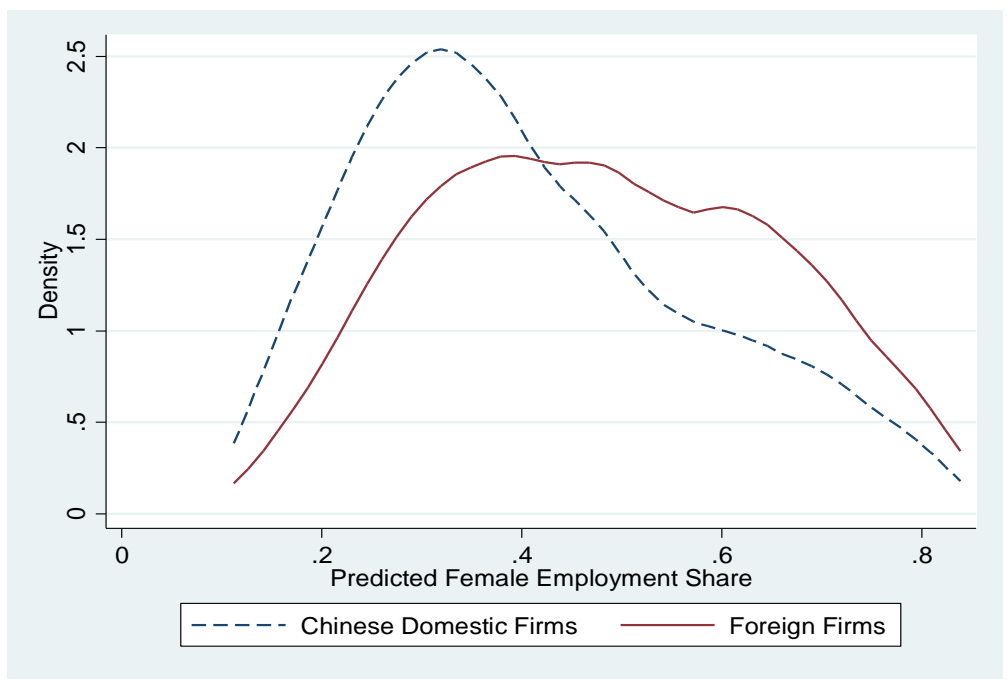

Source: NBS annual survey of industrial firms (2004) and authors' calculation

Figure 3: Long Diff in Standard Deviation of $\log (1+\gamma)$ and Multinationals' Output Share by Sector (2004-2007)

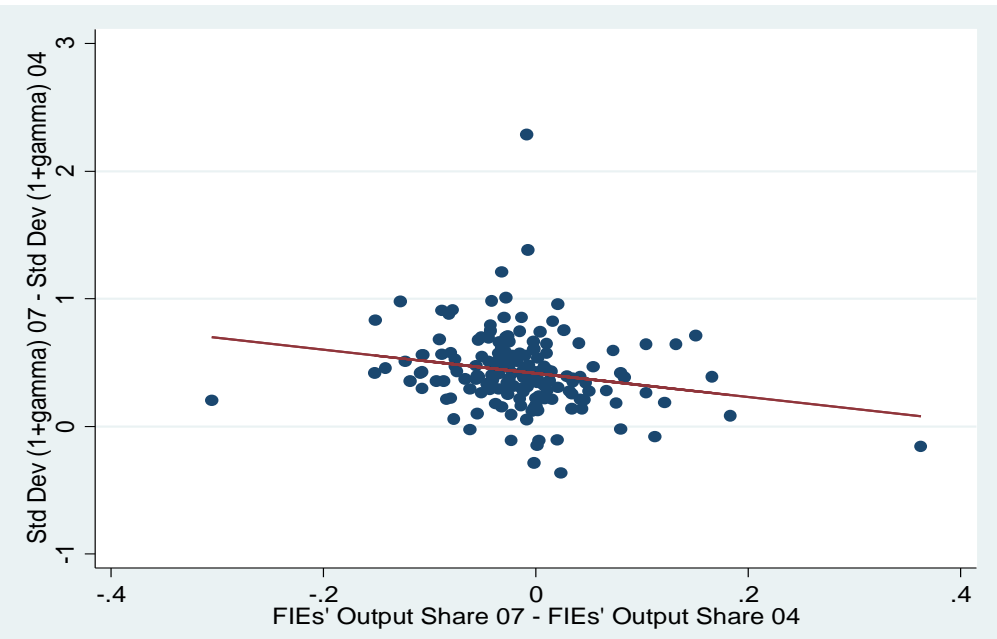

Source: NBS annual survey of industrial firms (2004) and authors' calculation 
Table 1: Country-Level Gender Inequality Indices

\begin{tabular}{|c|c|c|c|c|c|}
\hline & Country & Index & & Country & Index \\
\hline \multicolumn{6}{|c|}{ Panel A: UNDP Gender Inequality Index (High value means more unequal) } \\
\hline \multicolumn{3}{|c|}{ Top 5} & \multicolumn{3}{|c|}{ Bottom 5} \\
\hline 1 & Sweden & 0.065 & 1 & Saudi Arabia & 0.685 \\
\hline 2 & Denmark & 0.068 & 2 & India & 0.637 \\
\hline 3 & Netherlands & 0.077 & 3 & UAE & 0.602 \\
\hline 4 & Norway & 0.083 & 4 & Indonesia & 0.549 \\
\hline 5 & Switzerland & 0.084 & 5 & Cambodia & 0.548 \\
\hline
\end{tabular}

Panel B: World Value Survey Index (High value means more equal)

\begin{tabular}{llllll} 
& \multicolumn{2}{r}{ Top 5 } & & \multicolumn{3}{c}{ Bottom 5 } & \\
1 & Sweden & 0.876 & 1 & India & 0.446 \\
2 & Norway & 0.875 & 2 & Iran & 0.497 \\
3 & France & 0.815 & 3 & Malaysia & 0.556 \\
4 & Finland & 0.797 & 4 & Indonesia & 0.569 \\
5 & Canada & 0.792 & 5 & Vietnam & 0.571 \\
\hline \hline
\end{tabular}

Source: United Nations Development Program (UNDP) and World Value Survey (WVS). 
Table 2: Summary Statistics of the 2004 Cross-Sectional Sample

\begin{tabular}{|c|c|c|c|}
\hline Variable & Nb Obs & Mean & St Dev. \\
\hline \multicolumn{4}{|c|}{ Firm Level } \\
\hline \multicolumn{4}{|l|}{ Female employment share } \\
\hline all workers & 258,899 & 0.411 & 0.243 \\
\hline unskilled workers & 240,787 & 0.437 & 0.299 \\
\hline skilled workers & 255,239 & 0.370 & 0.230 \\
\hline domestic Chinese firms & 202,536 & 0.390 & 0.236 \\
\hline foreign invested enterprises (FIEs) & 28,450 & 0.482 & 0.256 \\
\hline \multicolumn{4}{|l|}{ Likelihood of a female manager } \\
\hline all firms & 217,181 & 0.246 & 0.277 \\
\hline domestic Chinese firms & 170,501 & 0.243 & 0.277 \\
\hline foreign invested enterprises (FIEs) & 23,243 & 0.255 & 0.273 \\
\hline \multicolumn{4}{|c|}{ Other firm characteristics used as regressors } \\
\hline computer intensity & 278,507 & 0.147 & 19.336 \\
\hline R\&D intensity & 272,948 & 0.031 & 0.054 \\
\hline $\ln (\mathrm{TFP})$ & 241,866 & -0.972 & 1.071 \\
\hline skill intensity & 278,507 & 0.012 & 0.053 \\
\hline capital intensity & 255,449 & 100.879 & 1,046 \\
\hline output & 275,460 & 72,743 & 656,030 \\
\hline profit rate & 249,424 & 0.025 & 0.084 \\
\hline age & 278,563 & 8.934 & 10.891 \\
\hline \multicolumn{4}{|c|}{ Country Level } \\
\hline Gender inequality index & 137 & 0.419 & 0.195 \\
\hline World Value Survey index & 58 & 0.649 & 0.124 \\
\hline In(GDP per capita) & 137 & 8.060 & 1.671 \\
\hline \multicolumn{4}{|c|}{ Industry Level } \\
\hline Female comparative advantage (3-digit) & 166 & 0.309 & 0.110 \\
\hline Foreign output share (4-digit) & 482 & 0.344 & 0.218 \\
\hline Herfindhal index (4-digit) & 482 & 0.049 & 0.076 \\
\hline Import-output ratio (4-digit) & 482 & 0.272 & 0.300 \\
\hline \multicolumn{4}{|c|}{ City Level } \\
\hline Foreign output share (city) & 345 & 0.155 & 0.182 \\
\hline
\end{tabular}

Source: NBS above-scale annual survey of industrial firms (2004).

Note: See definitions in Table A2 in the appendix. 
Table 3: Gender Cultural Transfers
(1)
(2)
(3)
(4)
(5)
(6)
(7)

Sample:

All Foreign Invested Firms in 2004

Dependent Variable: $\quad$ Female Share in Total Emp

Female Share in Female Share Prob. of Female Female Share

Unskilled Emp in Skilled Emp $\quad$ Manager $\quad$ in Total Emp

\begin{tabular}{|c|c|c|c|c|c|c|c|}
\hline Gender inequality index (GII) & $\begin{array}{c}-0.059 \\
(-2.14)^{* *}\end{array}$ & $\begin{array}{c}-0.099 \\
(-4.34)^{* * *}\end{array}$ & & $\begin{array}{c}-0.113 \\
(-3.98)^{* * *}\end{array}$ & $\begin{array}{c}-0.073 \\
(-3.56)^{* * *}\end{array}$ & $\begin{array}{l}-0.123 \\
(-1.75)^{*}\end{array}$ & $\begin{array}{l}0.015 \\
(0.24)\end{array}$ \\
\hline WVS index & & & $\begin{array}{l}0.072 \\
(1.80)^{*}\end{array}$ & & & & \\
\hline GII * Female CA & & & & & & & $\begin{array}{c}-0.306 \\
(-2.93)^{* *}\end{array}$ \\
\hline $\ln$ (gdppc) & & $\begin{array}{l}0.003 \\
(0.87)\end{array}$ & $\begin{array}{l}0.005 \\
(1.08)\end{array}$ & $\begin{array}{l}0.006 \\
(1.34)\end{array}$ & $\begin{array}{l}0.001 \\
(0.15)\end{array}$ & $\begin{array}{l}0.005 \\
(0.78)\end{array}$ & $\begin{array}{l}0.001 \\
(0.16)\end{array}$ \\
\hline Computer intensity & & $\begin{array}{l}-0.0007 \\
(-1.80)^{*}\end{array}$ & $\begin{array}{l}-0.0009 \\
(-1.70)^{*}\end{array}$ & $\begin{array}{c}-0.049 \\
(-3.54)^{* * *}\end{array}$ & $\begin{array}{c}-0.00057 \\
(-1.16)\end{array}$ & $\begin{array}{c}-0.032 \\
(-4.03)^{* * *}\end{array}$ & $\begin{array}{c}-0.0005 \\
(-2.90)^{* * *}\end{array}$ \\
\hline R\&D intensity & & $\begin{array}{c}-0.018 \\
(-1.73)^{*}\end{array}$ & $\begin{array}{l}-0.008 \\
(-1.21)\end{array}$ & $\begin{array}{l}0.013 \\
(0.79)\end{array}$ & $\begin{array}{l}-0.017 \\
(-1.35)\end{array}$ & $\begin{array}{c}-0.009 \\
(-4.52)^{* * *}\end{array}$ & $\begin{array}{c}-0.040 \\
(-2.04)^{* *}\end{array}$ \\
\hline $\ln (\mathrm{TFP})$ & & $\begin{array}{c}-0.028 \\
(-15.24)^{* * *}\end{array}$ & $\begin{array}{c}-0.023 \\
(-19.13)^{* * *}\end{array}$ & $\begin{array}{c}-0.021 \\
(-7.32)^{* * *}\end{array}$ & $\begin{array}{c}-0.027 \\
(-8.56)^{* * *}\end{array}$ & $\begin{array}{c}-0.026 \\
(-11.87)^{* * *}\end{array}$ & $\begin{array}{c}-0.024 \\
(-8.04)^{* * *}\end{array}$ \\
\hline Skill intensity & & $\begin{array}{l}0.029 \\
(0.32)\end{array}$ & $\begin{array}{c}-0.298 \\
(-5.65)^{* * *}\end{array}$ & $\begin{array}{c}-2.156 \\
(-7.35)^{* * *}\end{array}$ & $\begin{array}{c}0.248 \\
(2.49)^{* *}\end{array}$ & $\begin{array}{l}-0.032 \\
(-0.67)\end{array}$ & $\begin{array}{l}0.026 \\
(0.41)\end{array}$ \\
\hline $\ln$ (capital intensity) & & $\begin{array}{c}-0.040 \\
(-8.23)^{* * *}\end{array}$ & $\begin{array}{c}-0.031 \\
(-7.34)^{* * *}\end{array}$ & $\begin{array}{c}-0.036 \\
(-6.48)^{* * *}\end{array}$ & $\begin{array}{c}-0.026 \\
(-4.95)^{* * *}\end{array}$ & $\begin{array}{c}-0.087 \\
(-6.32)^{* * *}\end{array}$ & $\begin{array}{c}-0.038 \\
(-5.27)^{* * *}\end{array}$ \\
\hline $\ln$ (output) & & $\begin{array}{c}0.020 \\
(12.84)^{* * *}\end{array}$ & $\begin{array}{c}0.016 \\
(16.58)^{* * *}\end{array}$ & $\begin{array}{c}0.012 \\
(4.64)^{* * *}\end{array}$ & $\begin{array}{c}0.014 \\
(7.86)^{* * *}\end{array}$ & $\begin{array}{c}0.014 \\
(8.19)^{* * *}\end{array}$ & $\begin{array}{c}0.018 \\
(6.60)^{* * *}\end{array}$ \\
\hline $\ln$ (wage rate) & & $\begin{array}{c}-0.023 \\
(-8.05)^{* * *}\end{array}$ & $\begin{array}{c}-0.031 \\
(-12.12)^{* * *}\end{array}$ & $\begin{array}{c}-0.026 \\
(-6.15)^{* * *}\end{array}$ & $\begin{array}{c}-0.014 \\
(-4.24)^{* * *}\end{array}$ & $\begin{array}{c}-0.084 \\
(-7.21)^{* * *}\end{array}$ & $\begin{array}{c}-0.023 \\
(-6.29)^{* * *}\end{array}$ \\
\hline $\ln ($ firm age) & & $\begin{array}{c}0.004 \\
(2.21)^{* *}\end{array}$ & $\begin{array}{c}0.006 \\
(8.31)^{* * *}\end{array}$ & $\begin{array}{l}0.003 \\
(0.85)\end{array}$ & $\begin{array}{c}0.003 \\
(1.73)^{*}\end{array}$ & $\begin{array}{l}0.004 \\
(1.54)\end{array}$ & $\begin{array}{c}0.005 \\
(2.14)^{* *}\end{array}$ \\
\hline Industry fixed effects & $\mathrm{Y}$ & $\mathrm{Y}$ & $\mathrm{Y}$ & $\mathrm{Y}$ & $\mathrm{Y}$ & $\mathrm{Y}$ & $\mathrm{Y}$ \\
\hline Province fixed effects & $\mathrm{Y}$ & $\mathrm{Y}$ & $\mathrm{Y}$ & $\mathrm{Y}$ & $\mathrm{Y}$ & $\mathrm{Y}$ & $\mathrm{Y}$ \\
\hline $\begin{array}{l}\text { Number of Obs. } \\
\text { Adj. R-sq }\end{array}$ & $\begin{array}{c}12,345 \\
0.515 \\
\end{array}$ & $\begin{array}{c}11,504 \\
0.568 \\
\end{array}$ & $\begin{array}{l}9,015 \\
0.541 \\
\end{array}$ & $\begin{array}{c}10,416 \\
0.463 \\
\end{array}$ & $\begin{array}{c}11,465 \\
0.363 \\
\end{array}$ & $\begin{array}{l}7,884 \\
0.156 \\
\end{array}$ & $\begin{array}{c}10,693 \\
0.576 \\
\end{array}$ \\
\hline
\end{tabular}

Notes: t-statistics based on standard errors clustered at the country level are reported in the parentheses. ${ }^{*}, * *$, and $* * *$ indicate significance at the $10 \%$, $5 \%$, and $1 \%$ levels, respectively. 
Table 4: Firms' Female Labor Share and Profitability - 2004-2007 Panel Regressions

\begin{tabular}{|c|c|c|c|c|}
\hline & (1) & (2) & (3) & (4) \\
\hline Sample: & All Firms & Domestic Firms & All Firms & Domestic Firms \\
\hline Dependent Variable: & \multicolumn{4}{|c|}{ Profit/ Sales } \\
\hline Female labor share & $\begin{array}{c}0.003 \\
(3.13)^{* * *}\end{array}$ & $\begin{array}{c}0.002 \\
(1.75)^{*}\end{array}$ & $\begin{array}{l}-0.002 \\
(0.96)\end{array}$ & $\begin{array}{l}-0.003 \\
(1.03)\end{array}$ \\
\hline Female labor share $\mathrm{x}$ female CA & & & $\begin{array}{c}0.015 \\
(2.36)^{* *}\end{array}$ & $\begin{array}{c}0.016 \\
(2.78)^{* * *}\end{array}$ \\
\hline Controls & $\mathrm{Y}$ & $\mathrm{Y}$ & $\mathrm{Y}$ & $\mathrm{Y}$ \\
\hline Year fixed effects & $\mathrm{Y}$ & $\mathrm{Y}$ & $\mathrm{Y}$ & $\mathrm{Y}$ \\
\hline Firm fixed effects & $\mathrm{Y}$ & $\mathrm{Y}$ & $\mathrm{Y}$ & $\mathrm{Y}$ \\
\hline Number of Obs. & $1,060,883$ & 832,271 & $1,060,883$ & 832,271 \\
\hline adj. R-sq & 0.542 & 0.549 & 0.548 & 0.533 \\
\hline
\end{tabular}

Notes: Firms' R\&D intensity, capital intensity, wage rate, firm age and firm employment are included as control variables. t-statistics based on standard errors clustered at the four-digit industry are reported in the parentheses. *, **, and $* * *$ indicate significance at the $10 \%, 5 \%$, and $1 \%$ levels, respectively. 
Table 5: Gender Cultural Spillovers (Across Industries)

\begin{tabular}{|c|c|c|c|c|c|c|c|}
\hline & (1) & $(2)$ & (3) & (4) & (5) & (6) & (7) \\
\hline Sample: & \multicolumn{2}{|c|}{2004 Domestic Firms } & \multicolumn{5}{|c|}{ 2004-2007 Domestic Firm Panel } \\
\hline Dependent Variable: & Female Labor Share & $\begin{array}{c}\text { Prob. of Female } \\
\text { Manager }\end{array}$ & & & nale Labor s & & \\
\hline $\mathrm{FDI}_{\text {ind }}$ & $\begin{array}{c}0.321 \\
(4.11)^{* * *}\end{array}$ & $\begin{array}{c}0.047 \\
(3.43)^{* * *}\end{array}$ & $\begin{array}{c}0.032 \\
(5.21)^{* * *}\end{array}$ & $\begin{array}{c}0.045 \\
(4.21)^{* * *}\end{array}$ & $\begin{array}{l}-0.012 \\
(-1.42)\end{array}$ & $\begin{array}{c}-0.020 \\
(-2.19)^{* *}\end{array}$ & $\begin{array}{c}0.059 \\
(2.31)^{* *}\end{array}$ \\
\hline $\mathrm{FDI}_{\text {ind }} \times \mathrm{GII}_{\text {ind }}$ & & & & $\begin{array}{c}-0.049 \\
(-3.33)^{* * *}\end{array}$ & & & $\begin{array}{c}-0.387 \\
(-2.01)^{* *}\end{array}$ \\
\hline $\mathrm{FDI}_{\text {ind }} \times \mathrm{WVS}_{\text {ind }}$ & & & & & $\begin{array}{c}0.067 \\
(3.71)^{* * *}\end{array}$ & & \\
\hline $\mathrm{FDI}_{\text {ind }} \mathrm{x}$ female $\mathrm{CA}_{\text {ind }}$ & & & & & & $\begin{array}{c}0.192 \\
(4.53)^{* * *}\end{array}$ & \\
\hline $\mathrm{FDI}_{\text {ind }} \times \mathrm{GII}_{\text {ind }} \mathrm{x}$ female $\mathrm{CA}_{\text {ind }}$ & & & & & & & $\begin{array}{c}0.893 \\
(2.41)^{* *}\end{array}$ \\
\hline (Import/ Output) $)_{\text {ind }}$ & $\begin{array}{c}-0.132 \\
(-3.62)^{* * *}\end{array}$ & $\begin{array}{c}-0.213 \\
(-1.93)^{*}\end{array}$ & $\begin{array}{l}-0.017 \\
(-1.53)\end{array}$ & $\begin{array}{c}-0.016 \\
(-2.53)^{* *}\end{array}$ & $\begin{array}{c}-0.018 \\
(-2.09)^{* *}\end{array}$ & $\begin{array}{l}-0.005 \\
(-0.66)\end{array}$ & $\begin{array}{l}-0.005 \\
(-0.69)\end{array}$ \\
\hline Herfindahl $_{\text {ind }}$ & $\begin{array}{c}-0.122 \\
(-3.69)^{* * *}\end{array}$ & $\begin{array}{l}0.025 \\
(0.56)\end{array}$ & $\begin{array}{c}-0.035 \\
(-2.34)^{* *}\end{array}$ & $\begin{array}{c}-0.055 \\
(-3.69)^{* * *}\end{array}$ & $\begin{array}{c}-0.051 \\
(-3.71)^{* * *}\end{array}$ & $\begin{array}{c}-0.063 \\
(-1.99)^{* *}\end{array}$ & $\begin{array}{c}-0.068 \\
(-1.97)^{* *}\end{array}$ \\
\hline Controls & $\overline{\mathrm{Y}}$ & $\overline{\mathrm{Y}}$ & $\mathrm{Y}$ & $\bar{Y}$ & $\bar{Y}$ & $\overline{\mathrm{Y}}$ & $\overline{\mathrm{Y}}$ \\
\hline Province fixed effects & $\mathrm{Y}$ & $\mathrm{Y}$ & - & - & - & - & - \\
\hline Year fixed effects & - & - & $\mathrm{Y}$ & $\mathrm{Y}$ & $\mathrm{Y}$ & $\mathrm{Y}$ & $\mathrm{Y}$ \\
\hline Firm fixed effects & - & - & $\mathrm{Y}$ & $\mathrm{Y}$ & $\mathrm{Y}$ & $\mathrm{Y}$ & $\mathrm{Y}$ \\
\hline $\begin{array}{l}\text { Number of Obs. } \\
\text { Adj. R-sq }\end{array}$ & $\begin{array}{c}187,885 \\
0.138\end{array}$ & $\begin{array}{c}155,717 \\
0.046\end{array}$ & $\begin{array}{c}800,907 \\
0.754\end{array}$ & $\begin{array}{c}800,907 \\
0.794\end{array}$ & $\begin{array}{c}800,907 \\
0.793\end{array}$ & $\begin{array}{c}800,907 \\
0.793\end{array}$ & $\begin{array}{c}800,907 \\
0.794\end{array}$ \\
\hline
\end{tabular}

Notes: FDI $_{\text {ind }}$ stands for the share of output by FIEs in the industry. GII $_{\text {ind }}$ and WVS $_{\text {ind }}$ are the weighted averages of the FIEs' home countries' GII and WVS, respectively, with weights equal to each FIE's output share in the industry. All regressions include R\&D intensity, ln(TFP), $\ln$ (capital intensity), $\ln$ (output), $\ln$ (wage rate) and $\ln$ (firm age) as control variables. The 2004 regressions include the control of skill intensity, which is not available in other years. See Table A2 in the appendix for the definition and construction of each variable. t-statistics based on standard errors clustered at the four-digit industry are reported in the parentheses. *, **, and *** indicate significance at the $10 \%$, $5 \%$, and $1 \%$ levels, respectively. 
Table 6: Gender Cultural Spillovers (Across Cities)

\begin{tabular}{|c|c|c|c|c|c|}
\hline \multirow{3}{*}{$\begin{array}{l}\text { Sample: } \\
\text { Dependent Variable: }\end{array}$} & (1) & (2) & (3) & (4) & (5) \\
\hline & \multicolumn{2}{|c|}{2004 Domestic Firms } & \multicolumn{3}{|c|}{ 2004-2007 Domestic Firm Panel } \\
\hline & Female Labor & Prob. of Female & & ale Labor s & \\
\hline $\mathrm{FDI}_{\text {city }}$ & $\begin{array}{c}0.095 \\
(4.57)^{* * *}\end{array}$ & $\begin{array}{c}0.048 \\
(4.52)^{* * *}\end{array}$ & $\begin{array}{c}0.092 \\
(5.17)^{* * *}\end{array}$ & $\begin{array}{c}0.108 \\
(5.36)^{* * *}\end{array}$ & $\begin{array}{c}0.046 \\
(3.34)^{* * *}\end{array}$ \\
\hline $\mathrm{FDI}_{\text {city }} \times \mathrm{GII}_{\text {city }}$ & & & & $\begin{array}{l}-0.152 \\
(1.89)^{*}\end{array}$ & \\
\hline $\mathrm{FDI}_{\text {city }} \times \mathrm{WVS}_{\text {city }}$ & & & & & $\begin{array}{c}0.092 \\
(2.03)^{* *}\end{array}$ \\
\hline (Avg Import/ Output) city & $\begin{array}{c}-0.121 \\
(-2.72)^{* * *}\end{array}$ & $\begin{array}{c}-0.015 \\
(-2.04)^{* *}\end{array}$ & $\begin{array}{c}-0.017 \\
(-2.46)^{* * *}\end{array}$ & $\begin{array}{c}-0.019 \\
(-3.07)^{* * *}\end{array}$ & $\begin{array}{c}-0.018 \\
(2.23)^{* * *}\end{array}$ \\
\hline$(\text { Avg Herfindahl })_{\text {city }}$ & $\begin{array}{l}-0.434 \\
(-1.51)\end{array}$ & $\begin{array}{c}-0.124 \\
(-2.89)^{* * *}\end{array}$ & $\begin{array}{l}-0.027 \\
(-0.85)\end{array}$ & $\begin{array}{c}-0.038 \\
(-1.70)^{*}\end{array}$ & $\begin{array}{l}-0.025 \\
(-1.51)\end{array}$ \\
\hline Controls & $\bar{Y}$ & $\bar{Y}$ & $\bar{Y}$ & $\mathrm{Y}$ & $\mathrm{Y}$ \\
\hline Year fixed effects & - & - & $\mathrm{Y}$ & $\mathrm{Y}$ & $\mathrm{Y}$ \\
\hline Firm fixed effects & - & - & $\mathrm{Y}$ & $\mathrm{Y}$ & $\mathrm{Y}$ \\
\hline $\begin{array}{l}\text { Number of Obs. } \\
\text { Adj. R-sq }\end{array}$ & $\begin{array}{c}187,885 \\
0.068 \\
\end{array}$ & $\begin{array}{c}149,594 \\
0.015 \\
\end{array}$ & $\begin{array}{c}765,457 \\
0.797 \\
\end{array}$ & $\begin{array}{c}765,457 \\
0.810 \\
\end{array}$ & $\begin{array}{c}765,457 \\
0.803 \\
\end{array}$ \\
\hline
\end{tabular}

Notes: FDI ${ }_{\text {city }}$ stands for the share of output by FIEs in the city. GII $_{\text {city }}$ and WVS $_{\text {city }}$ are the weighted averages of the FIEs' home countries' GII and WVS, respectively, with weights equal to each FIE's output share in the industry. (Avg Import/ Output)city and (Avg Herfindahl)city are the weighted averages of the import-to-output ratios and Herfindahl index, respectively, across industries in the city, with weights equal to the output share of each industry. All regressions include R\&D intensity, $\ln (\mathrm{TFP}), \ln ($ capital intensity), $\ln ($ output), $\ln$ (wage rate) and $\ln ($ firm age) as control variables. The 2004 regressions include the control of skill intensity, which is not available for other years. See Table A2 in the appendix for the definition and construction of each variable. t-statistics based on standard errors clustered at the four-digit industry are reported in the parentheses. *, **, and ${ }^{* * *}$ indicate significance at the $10 \%, 5 \%$, and $1 \%$ levels, respectively. 
Table 7: TFP Gains by Removing Different Types of Distortions (\%)

\begin{tabular}{|c|c|c|c|c|c|}
\hline \multirow[t]{2}{*}{ Year } & \multicolumn{3}{|c|}{ Aggregate TFP Gain by Removing } & \multicolumn{2}{|c|}{$\begin{array}{l}\text { Contribution to Aggregate } \\
\text { TFP by Removing }\end{array}$} \\
\hline & (1) & $(2)$ & (3) & (4) & (5) \\
\hline & All Three Distortions & $\begin{array}{l}\text { Capital and Output } \\
\text { Distortions }\end{array}$ & $\begin{array}{l}\text { Gender and Output } \\
\text { Distortions }\end{array}$ & $\begin{array}{c}\text { Gender } \\
\text { Distortions }\end{array}$ & $\begin{array}{c}\text { Capital } \\
\text { Distortions }\end{array}$ \\
\hline 2004 & 100.26 & 95.26 & 66.24 & 4.99 & 33.93 \\
\hline 2005 & 94.75 & 89.49 & 65.42 & 5.55 & 30.95 \\
\hline 2006 & 96.79 & 91.49 & 68.38 & 5.47 & 29.35 \\
\hline 2007 & 96.10 & 90.75 & 68.11 & 5.56 & 29.13 \\
\hline
\end{tabular}

Notes: All numbers are $100 x\left(\left(\right.\right.$ TFP $\left.\left.^{\mathrm{e}} / \mathrm{TFP}\right)-1\right)$, where TFP $^{\mathrm{e}}$ stands for the efficient level of aggregate manufacturing TFP with all distortions removed. TFP in column 1 is constructed by keeping all firms' distortions. TFP in column 2 is constructed by setting all firms' gender discrimination factors, $\gamma$, to 0 , while TFP in column 3 is constructed by setting all firms' capital distortions, $\tau_{\mathrm{K}}$, to 0 . The last 2 columns report the contribution of removing each type of distortions to China's aggregate TFP gain in each sample year. 
Table 8: Correlation between FIEs' Output Share and the Dispersion of Firms' Gender Discrimination

\begin{tabular}{lccc}
\hline \hline & $(1)$ & $(2)$ & $(3)$ \\
Sample: & $2005-2007$ & $2006-2007$ & 2007 \\
\hline Dependent Variables: & $\Delta_{\mathrm{t}, \mathrm{t}-1} \mathrm{SD}(\log (1+\gamma))$ & $\Delta_{\mathrm{t}, \mathrm{t}-2} \mathrm{SD}(\log (1+\gamma))$ & $\Delta_{\mathrm{t}, \mathrm{t}-\mathrm{S}} \mathrm{SD}(\log (1+\gamma))$ \\
\hline & & & \\
$\Delta_{\mathrm{t}, \mathrm{t}-\mathrm{k}}$ FIE Output Share & -0.443 & -0.689 & -0.929 \\
& $(-1.31)$ & $(-2.52)^{* *}$ & $(-2.86)^{* * *}$ \\
\hline Number of Obs. & 498 & 332 & 166 \\
Adj. R-sq & 0.004 & 0.025 & 0.043 \\
\hline \hline
\end{tabular}

Notes: Observations are at the sector-year level. $\Delta_{\mathrm{t}, \mathrm{t}-\mathrm{k}}$ is an operator that takes the first difference of the variable of interest between year $\mathrm{t}$ and $\mathrm{t}-\mathrm{k} . *, * *$, and $* * *$ indicate significance at the $10 \%, 5 \%$, and $1 \%$ levels, respectively. 


\title{
Appendix to Do Multinationals Transfer Culture? Evidence on Female Employment in China
}

\author{
Heiwai Tang* \\ Yifan Zhang ${ }^{\dagger}$ \\ Johns Hopkins University \\ Chinese University of Hong Kong
}

December 28, 2016

\begin{abstract}
This appendix provides proofs, data description, and additional empirical results omitted in the main text.
\end{abstract}

${ }^{*}$ Corresponding author. School of Advanced International Studies, Johns Hopkins University, 1717 Massachusetts Ave NW, Washington, DC 20036, USA. Email: hwtang@jhu.edu.

${ }^{\dagger}$ Department of Economics, Chinese University of Hong Kong, Shatin, New Territories, Hong Kong. Email: yifan.zhang@cuhk.edu.hk. 


\section{Theoretical Appendix}

\subsection{Set-up}

Our model is built on Acemoglu and Autor (2011) (AA hereafter). Before analyzing workers' labor supply decisions, let us describe firms' labor demand for each type of tasks. Each firm employs a continuum of tasks, indexed by $z \in[0,1]$. Output of industry $j$ requires possibly all task inputs, which for simplicity is described by the following production function:

$$
y_{j}=\int_{0}^{1} \beta_{j}(z) \ln y(z) d z .
$$

The importance of task $z$ in the production of $j$ is captured by a continuous measure of weights, $\beta_{j}(z)$. Consider two industries, $j$ and $j^{\prime}$, if $\beta_{j^{\prime}}(z)>\beta_{j}(z)$, task $z$ is used more intensively in the production of industry- $j$ goods. To preserve the constant-returns-to-scale (CRS) property of the industry's production function, we assume that $\int_{0}^{1} \beta_{j}(z) d z=1$. Each task $z$ combines skills $(S)$ and brawn $(B)$ inputs linearly as follows

$$
y(z)=B(z)+a(z) S(z) .
$$

Skills and brawn are assumed to be perfectly substitutable. Which one is used to produce task $z$ depends on the relative productivity of skills $(a(z))$ in delivering task $z$.

Now let us make two ranking assumptions. First, we rank tasks as follows:

\section{Assumption 1:}

$a(z)$ is continuously differentiable and strictly increasing in $z$.

In other words, skill inputs are more effective in delivering a high- $z$ task. Second, we rank industries such that an industry with a higher $j$ requires on "average" more skill inputs, as follows:

\section{Assumption 2:}

Industries are ranked in such a way so that $\int_{0}^{k} \beta_{j^{\prime}}(z) d z>\int_{0}^{k} \beta_{j}(z) d z$ for all $k<[0,1)$ if $j>j^{\prime}$.

Notice that the idea behind this inequality is similar to the concept of first order stochastic dominance. A stronger version of this assumption is that $\frac{d \beta_{j^{\prime}}(z)}{d z} \geq \frac{d \beta_{j}(z)}{d z}$ for all $z<[0,1]$ if $j>j^{\prime}$. In that case, the weights, $\beta_{j}(z)$ is increasing in $z$ faster than that in $\beta_{j}^{\prime}(z)$, or high- $z$ tasks are becoming increasingly more important.

Following AA, we derive the following proposition regarding the use of skills and brawn tasks.

Proposition A1 There exists a threshold $z_{j}^{*}$ for industry $j$ such that all firms within the industry will use brawn inputs for all tasks $z \leq z_{j}^{*}$ and skill inputs for all tasks $z>z_{j}^{*}$.

Proof. The formal proof of this lemma can be found in Acemoglu and Zilibotti (2001). The main 
idea behind the proof is intuitive. Given wages for both inputs, $w_{B}$ and $w_{S}$, consider the cutoff task $z_{j}^{*}$. One unit of $y\left(z_{j}^{*}\right)$ can be done at the same cost by using brawn only, which cost $w_{B}$ per unit, or skills only, which cost $\frac{w_{S}}{a\left(z^{*}\right)}$ per unit. Given Assumption $1, \frac{w_{S}}{a(z)}<w_{B}$ for all $z>z_{j}^{*}$. In other words, it is strictly less costly to produce any tasks with $z>z_{j}^{*}$ using skills only rather than brawn only or a mix of the two.

\subsection{The Law of One Price of Skills}

Owners of skills and brawn are free to switch between tasks and industries. Free labor mobility implies no wage arbitrage. The resulting law of one price of skills implies

$$
\begin{aligned}
& w_{B}=p_{j}(z) \text { for all } z \leq z_{j}^{*} \text { and all } j \\
& w_{S}=p_{j}(z) a(z) \text { for all } z>z_{j}^{*} \text { and all } j
\end{aligned}
$$

where $p_{j}(z)$ is the price of task $z$ used in industry $j$. In other words, given constant $w_{B}, w_{S}$, and $a(z), p_{j}(z)$ will adjust in such a way to make sure that the above equations will hold.

Given the Cobb-Douglas production function for each industry $j$, firms' demand for each type of skills can be pinned down as follows

$$
p_{j}(z) l_{j}(z)=\beta_{j}(z) T V C \text { for any } z \text { and } j
$$

where $T V C$ stands for total variable cost.

Thus, for any two tasks that use brawn inputs, the following equality needs to hold:

$$
\frac{p_{j}(z) B_{j}(z)}{\beta_{j}(z)}=\frac{p_{j}(z) B_{j}\left(z^{\prime}\right)}{\beta_{j}\left(z^{\prime}\right)} .
$$

Constant $w_{B}$ and $w_{S}$ across tasks imply

$$
\frac{B_{j}(z)}{\beta_{j}(z)}=\frac{B_{j}\left(z^{\prime}\right)}{\beta_{j}\left(z^{\prime}\right)}
$$

Similarly, for any two tasks that use skills, the demand for skill inputs satisfies:

$$
\frac{p_{j}(z) \alpha_{S}(z) S_{j}(z)}{\beta_{j}(z)}=\frac{p_{j}\left(z^{\prime}\right) \alpha_{S}\left(z^{\prime}\right) S_{j}\left(z^{\prime}\right)}{\beta_{j}\left(z^{\prime}\right)} \Longrightarrow \frac{S_{j}(z)}{\beta_{j}(z)}=\frac{S_{j}\left(z^{\prime}\right)}{\beta_{j}\left(z^{\prime}\right)} .
$$

Given a firm's total demand for brawn and skills $\left(B_{j}\right.$ and $\left.S_{j}\right)$, the demand for each type of inputs for task $z$ is

$$
\begin{aligned}
& B_{j}(z)=\left\{\begin{array}{cc}
\frac{\beta_{j}(z) B_{j}}{\beta_{j}} & \text { for all } z \leq z_{j}^{*} \\
0 & \text { otherwise }
\end{array}\right. \\
& S_{j}(z)=\left\{\begin{array}{cc}
\frac{\beta_{j}(z) S_{j}}{1-\beta_{j}} & \text { for all } z>z_{j}^{*}, \\
0 & \text { otherwise }
\end{array}\right.
\end{aligned}
$$


where $\beta_{j}=\int_{0}^{z_{j}^{*}} \beta_{j}(z) d z$.

\subsection{Labor Supply}

Let us now turn to the labor supply side of the model. The economy is endowed with two types of workers: male and female. Let us denote the mass of male workers and female workers by $M$ and $F$, respectively. Each worker is endowed with both skills and brawn inputs.

Consistent with the literature and empirical evidence, we assume that relative to male workers, female workers are endowed with more skills than brawn (e.g. Pitt, Rosenzweig, and Hassan, 2012). ${ }^{1}$ In other words, female workers have a comparative advantage in skill-intensive tasks. More formally, let $\theta_{l}^{s}$ and $\theta_{l}^{b}$ be the skill and brawn endowment of gender- $l$ worker, respectively. These assumptions about men's $(m)$ and women's comparative advantages imply that

$$
\frac{\theta_{m}^{S}}{\theta_{m}^{B}}>\frac{\theta_{f}^{S}}{\theta_{f}^{B}} .
$$

As in AA, each worker has 1 unit of time and has to decide how to allocate the time used to supply brawn or skills. The time budget constraints for each female and male workers are

$$
\begin{aligned}
& t_{f}^{B}+t_{f}^{S} \leq 1 \\
& t_{m}^{B}+t_{m}^{S} \leq 1 .
\end{aligned}
$$

Both female and male workers choose how much skill and brawn to supply, respectively, making the following wages:

$$
\begin{aligned}
& w_{f}=w_{B} \theta_{f}^{B} t_{f}^{B}+w_{S} \theta_{f}^{S}\left(1-t_{f}^{B}\right) \\
& w_{m}=w_{B} \theta_{m}^{B} t_{m}^{B}+w_{S} \theta_{m}^{S}\left(1-t_{m}^{B}\right),
\end{aligned}
$$

where $w_{B}$ and $w_{S}$ are the wage rates for 1 unit of brawn and skills, respectively. Thus, the supplies of skills and brawn in the aggregate economy are endogenous.

As we have shown above, the wage rates for each unit of skill and brawn are the same regardless of which task or industry it is employed. All men will choose $B$ if

$$
w_{B} \theta_{m}^{B}>w_{S} \theta_{m}^{S} \Rightarrow \frac{w_{B}}{w_{S}}>\frac{\theta_{m}^{S}}{\theta_{m}^{B}}
$$

while all female workers will choose $S$ if

\footnotetext{
${ }^{1}$ If this prediction is too strong, we can assume different distributions of brain and brawn endowments for male and female workers, with the mean brawn-to-brain ratio for the former higher than that of the latter, and the same variance.
} 


$$
w_{S} \theta_{f}^{S}>w_{B} \theta_{f}^{B} \Rightarrow \frac{w_{B}}{w_{S}}<\frac{\theta_{f}^{S}}{\theta_{f}^{B}} .
$$

Given assumption (A-3), it can be shown that in equilibrium, the following inequality will hold:

$$
\frac{\theta_{f}^{S}}{\theta_{f}^{B}}>\frac{w_{B}}{w_{S}}>\frac{\theta_{m}^{S}}{\theta_{m}^{B}}
$$

Therefore, we have the following lemma that is crucial for the rest of the theoretical analysis.

Lemma A1 In equilibrium with no wage arbitrage, all female workers choose to supply skills, while all male workers choose to supply brawn.

Proof. For the first inequality, suppose it does not hold and $\frac{\theta_{f}^{S}}{\theta_{f}^{B}} \leq \frac{w_{B}}{w_{S}}$ instead. $w_{S} \theta_{f}^{S} \leq w_{B} \theta_{f}^{B}$, which implies that all female workers will choose to supply brawn. Given assumption (A-3), $\frac{\theta_{m}^{S}}{\theta_{m}^{B}} \leq$ $\frac{w_{B}}{w_{S}}$ and $w_{S} \theta_{m}^{S} \leq w_{B} \theta_{m}^{B}$ and all males will choose to supply brawn as well. There is no supply of skills in the economy but from above, we know that for any positive $w_{B}$ and $w_{S}$, Proposition A1 shows that there will always be demand for skills. Thus, $\frac{\theta_{f}^{S}}{\theta_{f}^{B}}>\frac{w_{B}}{w_{S}}$. For the second inequality, suppose it does not hold and $\frac{\theta_{m}^{S}}{\theta_{m}^{B}} \geq \frac{w_{B}}{w_{S}} \Rightarrow w_{S} \theta_{m}^{S} \geq w_{B} \theta_{m}^{B}$, all male workers will choose to supply skills only and since we already showed that $\frac{\theta_{f}^{S}}{\theta_{f}^{B}}>\frac{w_{B}}{w_{S}} \Rightarrow w_{S} \theta_{f}^{S}>w_{B} \theta_{f}^{B}$, female workers also only supply skills. There will be no supply of brawn services in the economy, which is obviously inconsistent to what we have proved in Proposition A1. Thus, $\frac{w_{B}}{w_{S}}>\frac{\theta_{m}^{S}}{\theta_{m}^{B}}$.

This lemma implies a one-to-one mapping between female labor and skill supply, as well as male labor and brawn supply. Specifically, aggregating individuals' skill supplies in the economy gives $S=\theta_{f}^{S} F$ and that for brawn as $B=\theta_{f}^{S} M$.

Given no other intrinsic difference between workers beside gender, all female workers supply skills and get the same wage rate:

$$
w_{f}=w_{S} \theta_{f}^{S}
$$

while all male workers supply brawn and get

$$
w_{m}=w_{B} \theta_{m}^{B}
$$

\subsection{Firm Equilibrium}

Consider an unbiased firm that assign the two types of labor inputs to different tasks based on their task-specific labor productivities according to (A-2). According to Proposition A1, for all tasks $z \geq z_{j}^{*}$, only skill inputs will be used in industry $j$, while for all tasks $z<z_{j}^{*}$, only brawn inputs will be used. A combination of that proposition and the lemma in the previous section implies the following corollary. 
Corollary A1 Only female workers will be hired to do tasks $z \geq z_{j}^{*}$; while only male workers will be hired to do tasks $z<z_{j}^{*}$.

We can thus rewrite the production function (A-1) for an unbiased firm in industry $j$ as

$$
y_{j}=\varphi_{i} \widetilde{\mu}_{j} S^{\beta_{j}} B^{1-\beta_{j}}
$$

where $\varphi_{i}$ is firm $i$ 's TFP; $\widetilde{\mu}_{j}=\exp \int_{z_{j}^{*}}^{1} \beta(z) \log a(z) d z ;$ and $\beta_{j}=\int_{z_{j}^{*}}^{1} \beta_{j}(z) d z$.

Since all skills are supplied by women while all brawn inputs are supplied by men, the production function can be re-written as

$$
y_{j}=\varphi_{i} \mu_{j} f^{\beta_{j}} m^{1-\beta_{j}}
$$

where $\mu_{j}=\left(\theta_{f}^{S}\right)^{\beta_{j}}\left(\theta_{m}^{B}\right)^{1-\beta_{j}} \widetilde{\mu}_{j}$.

\subsubsection{Statistical Discrimination}

Now let us study the behavior of firms with statistical discrimination. A biased firm perceives a lower productivity of female workers compared to their true levels. Specifically, it thinks that if a female worker supplies an input (either skill or brawn), her productivity is a fraction $\lambda \in(0, \infty)$ of the true productivity. A firm with $\lambda=1$ is completely neutral to female workers. $\lambda<1$ indicates an increasingly more negative view toward women while $\lambda>1$ indicates a more favorable view, relative to the firm's view toward male workers.

The firm will still employ women for the very skill-intensive tasks because of their comparative advantage, but it will use more men for intermediate skilled tasks that should be (optimally) done by women.

We have the following proposition for biased firms, which complements Proposition A1:

Proposition A2 There exists a firm-specific threshold $z_{j}^{*}(\lambda)$ for industry $j$ such that it will use brawn inputs for all tasks $z \leq z_{j}^{*}(\lambda)$ and skill inputs for all tasks $z>z_{j}^{*}(\lambda)$. $\frac{\partial z_{j}^{*}(\gamma)}{\partial \lambda}<0$.

Proof. Again, the formal proof of this lemma can be found in Acemoglu and Zilibotti (2001). Similar to the previous proof, the task cutoff $z_{j}^{*}(\lambda)$, above which all tasks are done by skill inputs, is determined by the indifference condition: $w_{B}=\frac{w_{S}}{\lambda a\left(z^{*}\right)}$. Given that $a(z)$ is increasing in $z$ (Assumption 1), $\frac{w_{S}}{\lambda a(z)}<w_{B}$ for all $z>z_{j}^{*}(\lambda)$. It is strictly less costly to produce any tasks with $z>z_{j}^{*}(\lambda)$ using skills only rather than brawn only or a mix of the two. Moreover, since $a(z)$ is increasing in $z$, a lower $\lambda$ (a stronger bias) implies a higher $z_{j}^{*}(\lambda)$.

We can then express the production function of a biased firm as

$$
y_{j}(\lambda)=\varphi_{i} \mu_{j}(\lambda) f^{\beta_{j}(\lambda)} m^{1-\beta_{j}(\lambda)},
$$

where $\mu_{j}(\lambda)=\left(\theta_{f}^{S}\right)^{\beta_{j}(\lambda)}\left(\theta_{m}^{B}\right)^{1-\beta_{j}(\lambda)} \widetilde{\mu}_{j}$ and $\beta_{j}(\lambda)$ is decreasing strictly in $\lambda$. Thus, even when we assume no taste-based discrimination against women (i.e., $\gamma=0$ for all firms), firm heterogeneity in $\beta_{j}(\lambda)$ would give us heterogeneous female-to-male labor shares across firms. Specifically, by solving 
a firm's profit maximization problem, we obtain a different expression for the female-to-male ratio as

$$
\frac{f}{m}=\frac{\beta_{j}(\lambda)}{1-\beta_{j}(\lambda)} \frac{w_{m}}{w_{f}},
$$

which is decreasing in $\lambda$ for a given $\beta_{j}$.

\subsection{References}

Acemoglu, Daron, and Fabrizio Zilibotti (2001) "Productivity Differences" Quarterly Journal of Economics, 116(2), pp. 563-606. 
Table A1: Ranking of Chinese Characters as the Last Character in Female and Male Names

\begin{tabular}{ccccc}
\hline \hline \multicolumn{4}{c}{$\begin{array}{c}\text { Characters with Highest Female Name } \\
\text { Probability }\end{array}$} & $\begin{array}{c}\text { Characters with Lowest Female Name } \\
\text { Probability }\end{array}$ \\
\hline Rank & Character & Female Prob. & Character & Female Prob. \\
\hline 1 & 娟 & 0.997 & 彪 & 0.008 \\
2 & 媛 & 0.996 & 法 & 0.012 \\
3 & 娥 & 0.996 & 刚 & 0.012 \\
4 & 娇 & 0.995 & 财 & 0.018 \\
5 & 婵 & 0.994 & 山 & 0.019 \\
6 & 姐 & 0.992 & 豪 & 0.022 \\
7 & 菊 & 0.992 & 泰 & 0.023 \\
8 & 花 & 0.990 & 强 & 0.024 \\
9 & 翠 & 0.989 & 武 & 0.025 \\
10 & 莉 & 0.988 & 魁 & 0.026 \\
\hline \hline
\end{tabular}

Source: Authors' calculation using 20\% random extract of the 2005 1\% Population Census. 
Table A2: Variable Definitions and Data Sources

\begin{tabular}{|c|c|}
\hline Variable & Definition \\
\hline Female labor share & Number of female workers divided by total employment \\
\hline Female share in unskilled labor & $\begin{array}{l}\text { Number of female unskilled workers divided by total number of unskilled workers. Unskilled } \\
\text { labor is defined as workers with junior high school education level or below }\end{array}$ \\
\hline Female share skilled labor & $\begin{array}{l}\text { Number of female skilled workers divided by total number of skilled workers. Skilled labor is } \\
\text { defined as workers with at leat senior high school education level }\end{array}$ \\
\hline Gender Inequality Index (GII) & Country-level measure of gender inequality. Source: UNDP \\
\hline World Value Survey index & $\begin{array}{l}\text { World Value Survey Score in 2005. It is calculated based on Questions V44, V61 and V63 in } \\
\text { the survey. Source: World Value Survey }\end{array}$ \\
\hline $\begin{array}{l}\text { Female probability of legal person } \\
\text { representative }\end{array}$ & $\begin{array}{l}\text { The probability of a Chinese character being the last character of a woman's name. It is } \\
\text { calculated using equation (2) in the text }\end{array}$ \\
\hline $\ln ($ gdppc) & Natural log of the GDP per capita in 2004. Source: World Bank \\
\hline Computer intensity & Number of computers/total employment \\
\hline R\&D/value added & R\&D expenditure/total value added \\
\hline $\ln (\mathrm{TFP})$ & Total factor productivity calculated with Olley-Pakes procedure \\
\hline $\ln ($ capital intensity) & $\begin{array}{l}\text { Natural log of real capital stock/total employment. Real capital stock is calculated using the } \\
\text { prepetual inventory method in Brandt et al. (2012) }\end{array}$ \\
\hline $\ln$ (output) & Natural log of total output \\
\hline $\ln ($ wage rate) & Natural log of total wage/total employment \\
\hline $\ln ($ age) & Natural log of the number of years since the start date of the firm \\
\hline Profitability & Total profit/sales \\
\hline $\mathrm{FDI}_{\text {ind }}$ & Output share of foreign invested firms in a 4-digit industry \\
\hline FDI $_{\text {city }}$ & Output share of foreign invested firms in a city \\
\hline Herndahl index & Calculated from NBS annual industrial firm survey \\
\hline Import output ratio & Ratio of total imports to total domestic output at industry level \\
\hline Female comparative advantage & $\begin{array}{l}\text { Female share in total employment by industry. Source: Do, Levchenko and Raddatz (2016) } \\
\text { based on US Population Census Data. }\end{array}$ \\
\hline
\end{tabular}


Table A3: Top and Bottom 10 Three-Digit Industries Based on Female Comparative Advantage

\begin{tabular}{llclll}
\hline \hline $\begin{array}{l}\text { Industry } \\
\text { Code }\end{array}$ & \multicolumn{1}{c}{ Top 10 Industries } & $\begin{array}{c}\text { Female Labor } \\
\text { Share }\end{array}$ & $\begin{array}{l}\text { Industry } \\
\text { Code }\end{array}$ & Bottom 10 Industries & $\begin{array}{c}\text { Female Labor } \\
\text { Share }\end{array}$ \\
\hline 181 & Apparel & 0.650 & 312 & Cement Products & 0.103 \\
192 & Leather Products & 0.602 & 311 & Cement & 0.103 \\
193 & Fur Accessories & 0.595 & 322 & Steel Smelting & 0.131 \\
296 & Rubber Shoes & 0.563 & 323 & Steel Rolling & 0.131 \\
191 & Leather Accessories & 0.563 & 324 & Ferroalloy & 0.131 \\
182 & Textile Shoes & 0.563 & 321 & Iron & 0.131 \\
183 & Hat, Cap, and Millinery & 0.563 & 334 & Non-Ferrous Metall Alloys & 0.150 \\
176 & Knit Fabric & 0.561 & 201 & Saw, Wood Chips & 0.150 \\
174 & Cotton and Chemical Fiber & 0.540 & 291 & Automobile Tires & 0.156 \\
\hline \hline
\end{tabular}

Note: U.S. female share in total employment by sector. Source: Do, Levchenko, and Raddatz (2016). 
Table A4: The Impact of FDI on the Female Wage Discount by City

\begin{tabular}{|c|c|c|c|c|c|c|}
\hline & (1) & (2) & (3) & (4) & (5) & (6) \\
\hline Dependent Variable: & \multicolumn{3}{|c|}{$\begin{array}{c}\ln (\text { female wage/male wage) Estimated } \\
\text { Using All Individuals }\end{array}$} & \multicolumn{3}{|c|}{$\begin{array}{c}\ln \text { (female wage/male wage) Estimated } \\
\text { Using Individuals in Manufacturing } \\
\text { Sector Only }\end{array}$} \\
\hline \multirow{2}{*}{ FDI $_{\text {city }}$} & 0.192 & 0.189 & 0.407 & 0.314 & 0.322 & 0.633 \\
\hline & $(2.26)^{* *}$ & $(2.09)^{* *}$ & $(1.93)^{*}$ & $(2.05)^{* *}$ & $(1.92)^{*}$ & $(1.69)^{*}$ \\
\hline \multirow[t]{2}{*}{$\mathrm{FDI}_{\text {city }} \times \mathrm{GII}_{\text {city }}$} & & & -0.665 & & & -0.532 \\
\hline & & & $(-0.91)$ & & & $(-0.72)$ \\
\hline \multirow[t]{2}{*}{ Average years of schooling } & & 0.015 & 0.019 & & -0.004 & -0.001 \\
\hline & & $(0.76)$ & $(0.83)$ & & $(-0.16)$ & $(-0.35)$ \\
\hline \multirow[t]{2}{*}{$\ln$ (average wage rate) } & & -0.035 & -0.041 & & 0.038 & 0.034 \\
\hline & & $(-0.72)$ & $(-0.68)$ & & $(0.73)$ & $(0.78)$ \\
\hline Year fixed effects & $\mathrm{Y}$ & $\mathrm{Y}$ & $\mathrm{Y}$ & $\mathrm{Y}$ & $\mathrm{Y}$ & $\mathrm{Y}$ \\
\hline City fixed effects & $\mathrm{Y}$ & $\mathrm{Y}$ & $\mathrm{Y}$ & $\mathrm{Y}$ & $\mathrm{Y}$ & $\mathrm{Y}$ \\
\hline Number of Obs. & 723 & 723 & 618 & 711 & 711 & 592 \\
\hline Adj. R-sq & 0.484 & 0.483 & 0.458 & 0.367 & 0.365 & 0.328 \\
\hline
\end{tabular}

Notes: We conduct this exercise in two stages. In the first stage, we run individual level Mincer-type wage regressions for each city using the urban household data 2004-2007, and obtain the coefficient on the female dummy. We run this regression using all individuals and only those in the manufacturing sector. In the second stage, we run city-level regressions using the estimated female dummy from the first stage as the dependent variable. This table reports the regression results of the second stage. z-statistics based on bootstrapped standard errors are reported in the parentheses. FDI $_{\text {city }}$ stands for the share of output by FIEs in the city. GII city $_{\text {its }}$ the weighted average of the FIEs' home countries' GII, with weights equal to each FIE's output share in the industry. *, **, and *** indicate significance at the $10 \%, 5 \%$, and $1 \%$ levels, respectively. 
Table A5: Gender Cultural Spillovers (FDI Prevalence Measured by Foreign Firms' Employment Share)

\begin{tabular}{|c|c|c|c|c|}
\hline & (1) & (2) & (3) & (4) \\
\hline Sample: & \multicolumn{4}{|c|}{ 2004-2007 Domestic Firm Panel } \\
\hline Dependent Variable: & \multicolumn{4}{|c|}{ Female Labor Share } \\
\hline FDI & $\begin{array}{c}0.033 \\
(3.12)^{* * *}\end{array}$ & $\begin{array}{c}0.041 \\
(5.01)^{* * *}\end{array}$ & $\begin{array}{c}0.015 \\
(2.05)^{* *}\end{array}$ & $\begin{array}{c}0.043 \\
(1.77)^{*}\end{array}$ \\
\hline $\mathrm{FDI}_{\text {ind }} \times \mathrm{GII}_{\text {ind }}$ & & $\begin{array}{c}-0.032 \\
(-3.31)^{* * *}\end{array}$ & & $\begin{array}{c}-0.043 \\
(-3.39)^{* *}\end{array}$ \\
\hline $\mathrm{FDI}_{\text {ind }} \times \mathrm{WVS}_{\text {ind }}$ & & & $\begin{array}{c}0.056 \\
(2.96)^{* * *}\end{array}$ & \\
\hline $\mathrm{FDI}_{\text {ind }} \times \mathrm{GII}_{\text {ind }} \mathrm{x}$ female CA & & & & $\begin{array}{c}0.028 \\
(2.43)^{* *}\end{array}$ \\
\hline Controls & $\mathrm{Y}$ & $\mathrm{Y}$ & $\mathrm{Y}$ & $\mathrm{Y}$ \\
\hline Firm fixed effects & $\mathrm{Y}$ & $\mathrm{Y}$ & $\mathrm{Y}$ & $\mathrm{Y}$ \\
\hline Year fixed effects & $\mathrm{Y}$ & $\mathrm{Y}$ & $\mathrm{Y}$ & $\mathrm{Y}$ \\
\hline Number of Obs. & 800,907 & 800,907 & 800,907 & 800,907 \\
\hline Adj. R-sq & 0.794 & 0.794 & 0.794 & 0.794 \\
\hline
\end{tabular}

Notes: All regressions include the sector's Herfindahl index and import share, as well as the firm's R\&D intensity, $\ln (\mathrm{TFP}), \ln$ (capital intensity), $\ln$ (output), $\ln ($ wage rate) and $\ln$ (firm age) as control variables. t-statistics based on standard errors clustered at the four-digit industry are reported in the parentheses. ${ }^{*},{ }^{* *}$, and $* * *$ indicate significance at the $10 \%, 5 \%$, and $1 \%$ levels, respectively. 
Table A6: Gender Cultural Spillovers (All Regressors Lagged by One Year)

\begin{tabular}{|c|c|c|c|c|}
\hline & (1) & (2) & (3) & (4) \\
\hline Sample: & \multicolumn{4}{|c|}{ 2004-2007 Domestic Firm Panel } \\
\hline Dependent Variable: & \multicolumn{4}{|c|}{ Female Labor Share } \\
\hline $\mathrm{FDI}_{\text {ind, } \mathrm{t}-1}$ & $\begin{array}{c}0.027 \\
(3.56)^{* * *}\end{array}$ & $\begin{array}{c}0.060 \\
(4.76)^{* * *}\end{array}$ & $\begin{array}{l}-0.021 \\
(-1.44)\end{array}$ & $\begin{array}{c}0.071 \\
(2.45)^{* *}\end{array}$ \\
\hline $\mathrm{FDI}_{\text {ind, } \mathrm{t}-1} \times \mathrm{GII}_{\text {ind, } \mathrm{t}-1}$ & & $\begin{array}{c}-0.093 \\
(-5.01)^{* * *}\end{array}$ & & $\begin{array}{c}-0.419 \\
(-3.28)^{* *}\end{array}$ \\
\hline $\mathrm{FDI}_{\text {ind, } t-1} \mathrm{x} \mathrm{WVS}_{\text {ind, } t-1}$ & & & $\begin{array}{c}0.057 \\
(2.98)^{* * *}\end{array}$ & \\
\hline $\mathrm{FDI}_{\text {ind, t-1 }} \times \mathrm{GII}_{\text {ind, } \mathrm{t}-1} \mathrm{x}$ female CA & & & & $\begin{array}{c}0.774 \\
(2.86)^{* * *}\end{array}$ \\
\hline Controls & $\mathrm{Y}$ & $\mathrm{Y}$ & $\mathrm{Y}$ & $\mathrm{Y}$ \\
\hline Firm fixed effects & $\mathrm{Y}$ & $\mathrm{Y}$ & $\mathrm{Y}$ & $\mathrm{Y}$ \\
\hline Year fixed effects & $\mathrm{Y}$ & $\mathrm{Y}$ & $\mathrm{Y}$ & $\mathrm{Y}$ \\
\hline Number of Obs. & 684,304 & 684,304 & 684,304 & 684,304 \\
\hline Adj. R-sq & 0.809 & 0.796 & 0.795 & 0.809 \\
\hline
\end{tabular}

Notes: All regressions include lagged sectoral Herfindahl index and import share, as well as lagged firm's R\&D intensity, $\ln (T F P), \ln ($ capital intensity), $\ln$ (output), $\ln$ (wage rate) and $\ln ($ firm age) as control variables. t-statistics based on standard errors clustered at the four-digit industry are reported in the parentheses. *, **, and *** indicate significance at the $10 \%, 5 \%$, and $1 \%$ levels, respectively. 